\title{
Sylfemafildye Inhalfanex
}

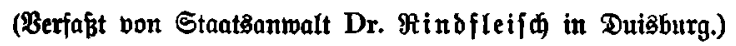

Die Bahlen bebeuten bie Seiten.

\section{Civiltedt.}

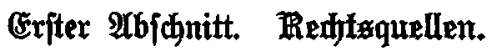

a) Beitlide Begrenzung der Anwenbbarteit ber Befege.

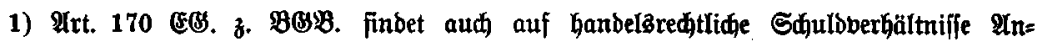

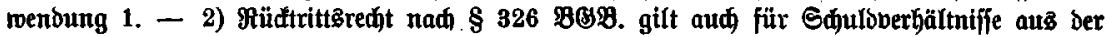
3eit bor 1900 45. - 3) Anfedtung ber Chelidfeit eines bor 1900 geborenen Sindes (nega=

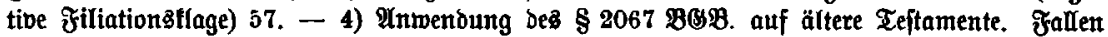

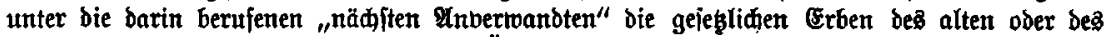

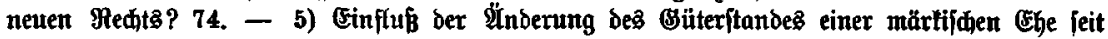
1. Yamuar 1900 auf ben borhes gemadten PReirgewinn aus cinem bejonderen Bewerbe ber

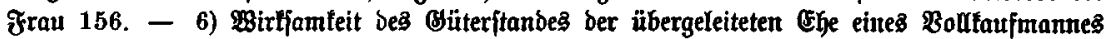
gegeniuber Dritten 158. - 7) Fortbeftehen alter (Erbzinšredte, Baubejüräntungen und Bor= faufgredte 203. - 8) Ort. 169 (E) ift auf $\$ 124$ BGB. nidht antwenobar 217. - 9) Folgen

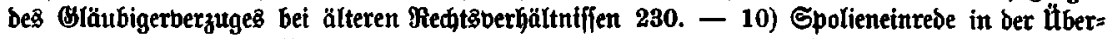

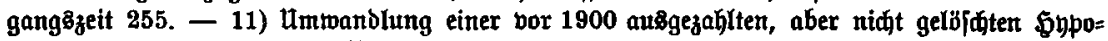

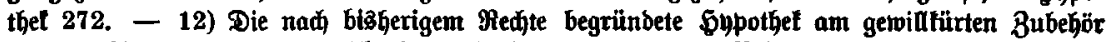
ift mit Arnlegung bes (s) runibudfes erlofden 273. - 13) Befugnis ber bor 1900 in fort=

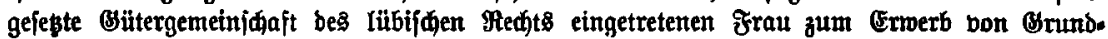
ftüden ohne bormurbinaftlidje (Benehmigung 283. - 14) Gine bor 1900 eingeleitete Ber=

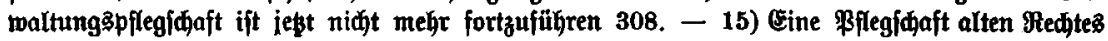

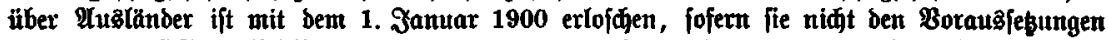

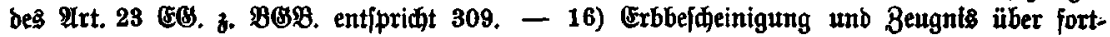
gejęte Bütergemein[djaft, wenn ber Chegatte bor 1900 geftorben ift 319. - 17) Der bor

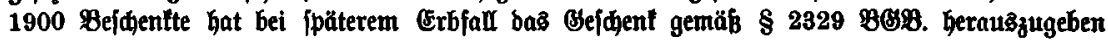
334. - 18) Ergänzung des erit burd $B(B 8$. eingefühtten Pflidtteiles megen Sđjenkungen

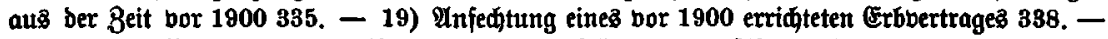

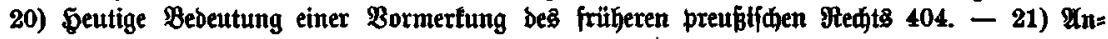

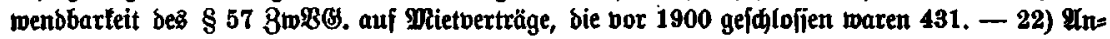

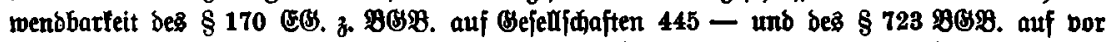

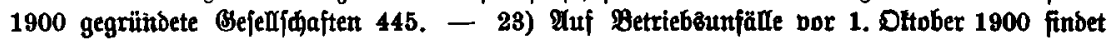

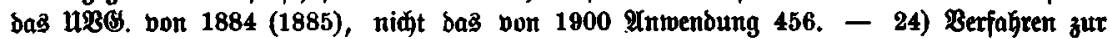

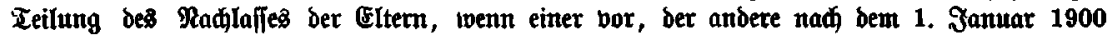
werftorben ift 484.

b) Statutenforrifion.

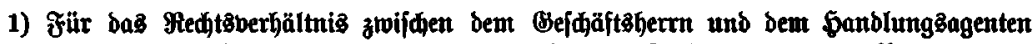

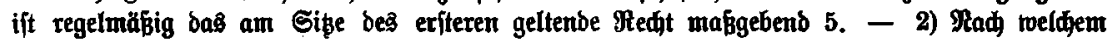

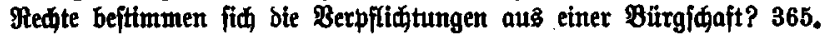

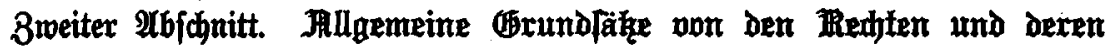 Dexfolgumg.}

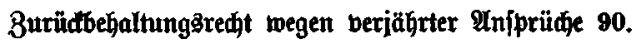




\section{Dritter $\mathfrak{A b j}$ fonitt. Bon Dem Ber[nmen.}

a) Bon ben natürliden Berfonen.

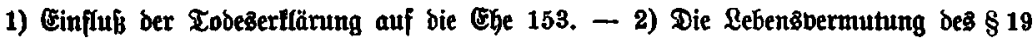

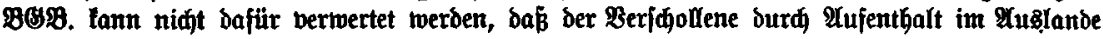
feine bisherige Staat\&angehörigleit verloren habe 305.

b) Bon ben juriftifden Berfonen.

Befugnis ber Borftandsmitglieber zur Anfedtung ber getidftsjeitigen Beftellung bon Siquibatoren eines aufgelöften Bereineş 344.

\section{Bierter 26 fdnitt. Don Dem Badjen.}

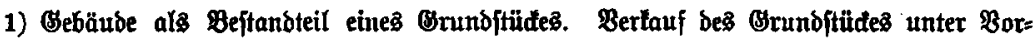
behalt beş Eigentum

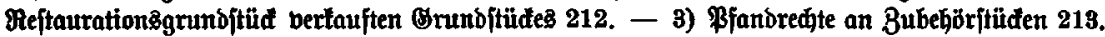
270. - 4) (Figentumbborbegalt an Beftandteilen einer Sache 214. - 5) Jaloufien finb mejent=

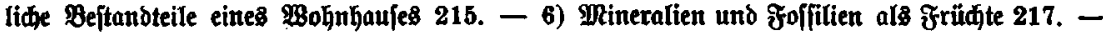

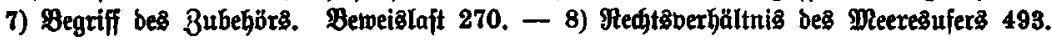

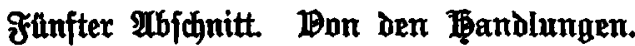

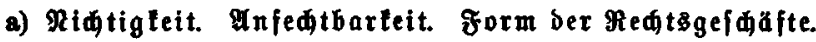

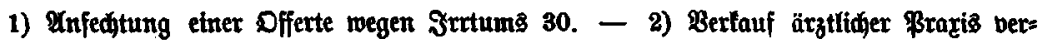

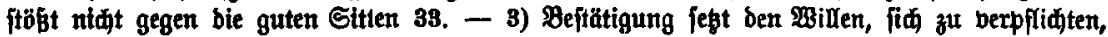

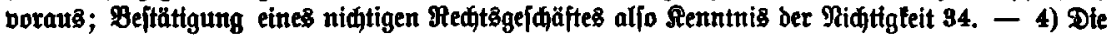

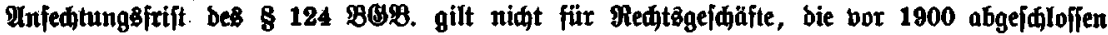
finb 217. - 5) Die פingabe eines Darlehns ober bie Rieferung bon \$Beinen zur Berwentung

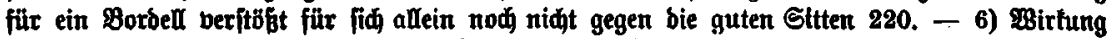

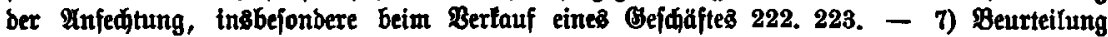

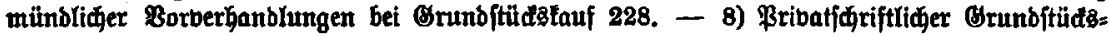

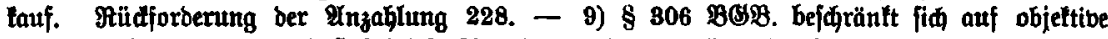

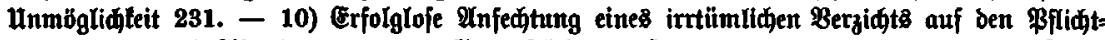

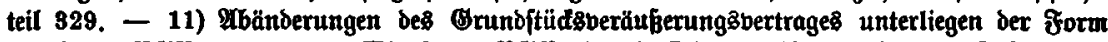

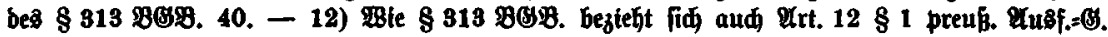

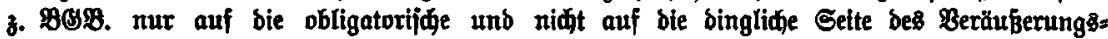

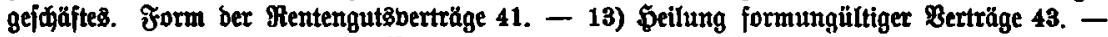

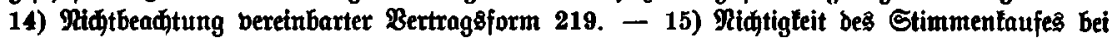
Bef. m. b. 5. 503 .

b) Rebenbeftimmung bei Ređtgefdäften. Bedingung.

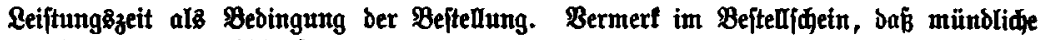
Rebenverabrebungen $\mathfrak{u n g u ̈ l t i g}$ feien $\mathbf{3 5}$.

c) $\mathfrak{B}$ illensertlärung. Stellbertretung.

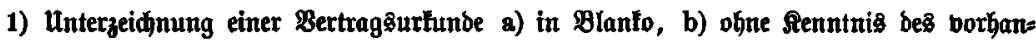

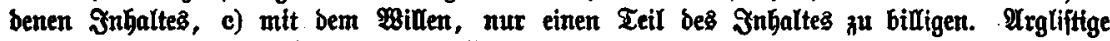

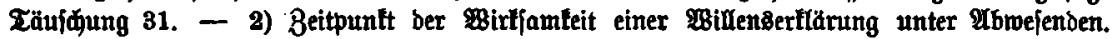

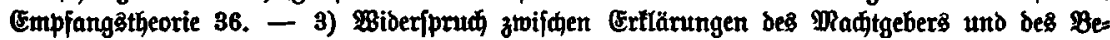
bollmädttgten. Ungiilttgteit einer Benteralbollmad,t, nad ber ber Padatgeber unbejaräntt in

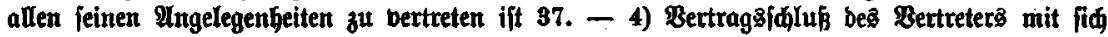

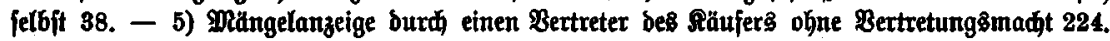

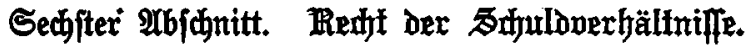

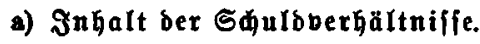

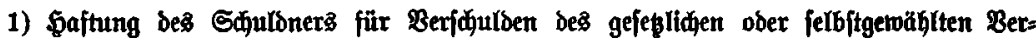

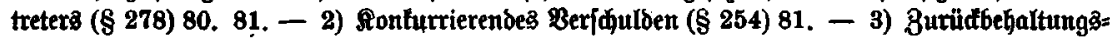




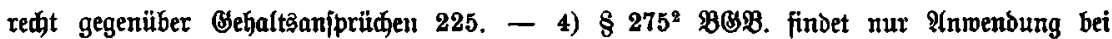

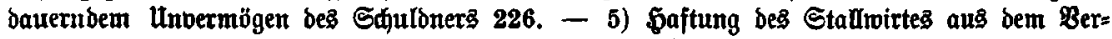

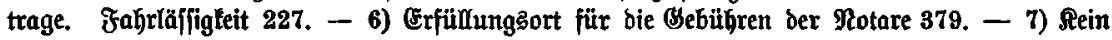

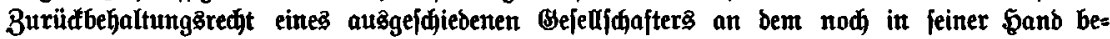

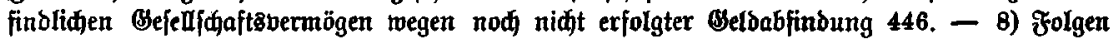
bes Bัläubigerberzuges 230.

\section{b) Sduldberbältnifie aus Berträgen.}

1) Beftimmung ber Reiftung burd einen Dritten. Folgen ber BBeigerung beș Dritten 7. -

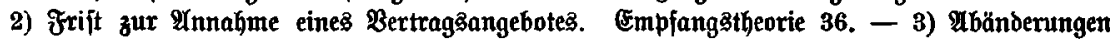

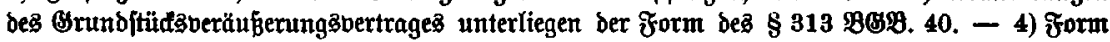

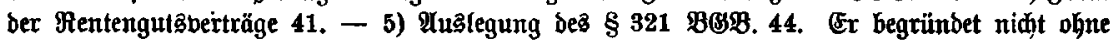

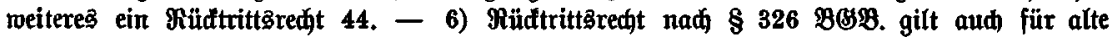

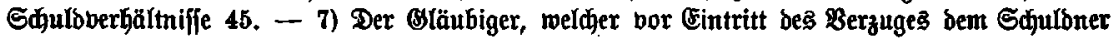

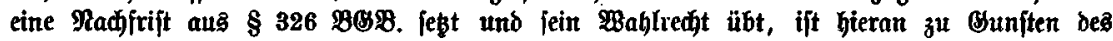

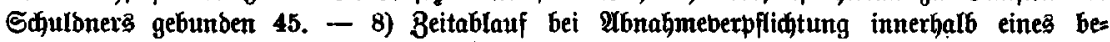

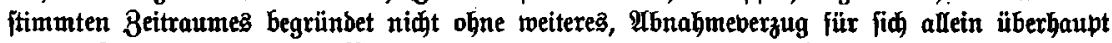

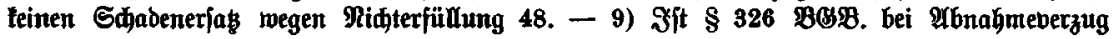

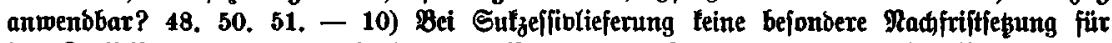

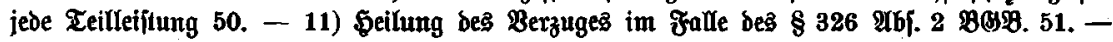

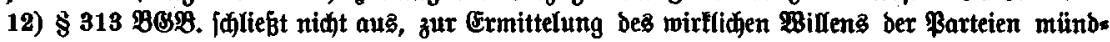

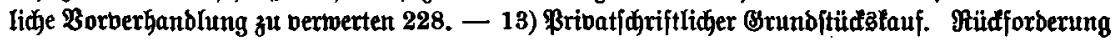

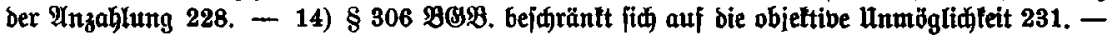

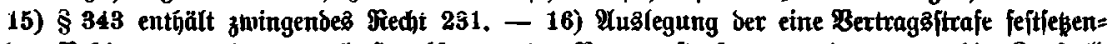

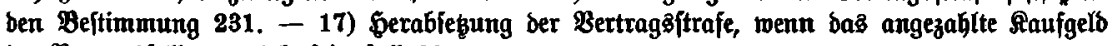
im Berzuggfalle vermirft fein foll 232.

\section{c) Erlöfdeñ ber Sdulbberhăltniffe.}

1) Erfü̈ung burळ Siroüberweifung 76. - 2) Soften ber Duittung 271. - 3) Đinter=

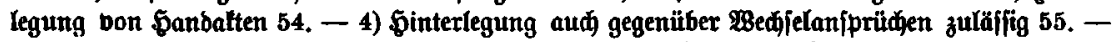

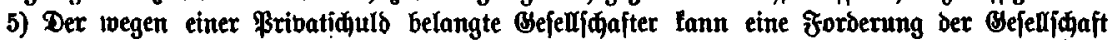

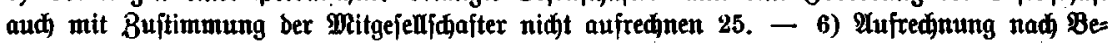

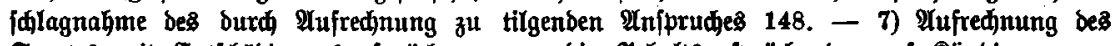

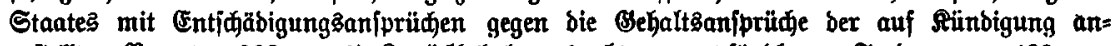

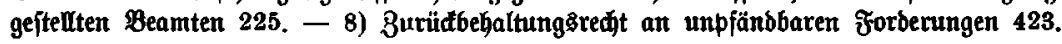

d) iłbertragung ber Forberung.

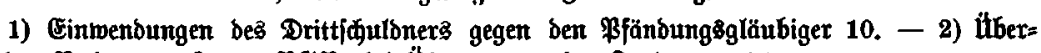

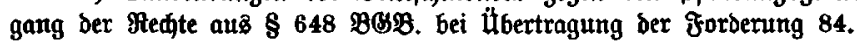

e) Sdulbübernabme.

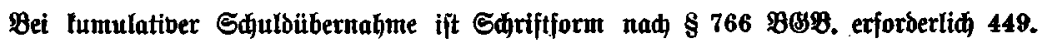

\section{f) Sinzelne ఠdulbberhălniffe.}

\section{Rauf. Tauld.}

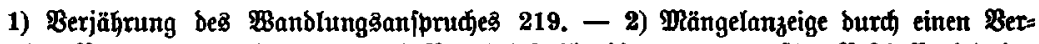

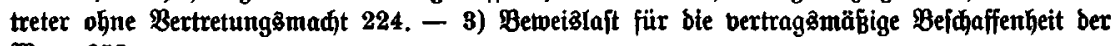
Bare 355 .

Darlehn zu Spielzzoefen 448.

2. Dariegn.

3. Dienfitbertrag.

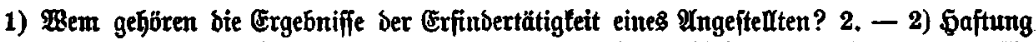

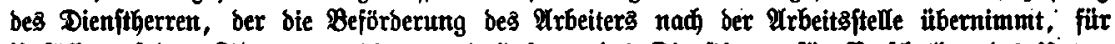

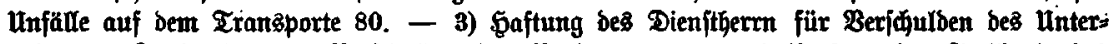
gebenten. Ronturrierendes Beridulden bes Berlez̧ten 81. - 4) Umfang der Sadhunde bes Dienftberpfliditeten 83. 


\section{Wertbertrag.}

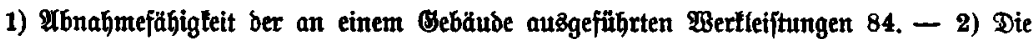

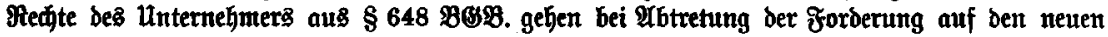

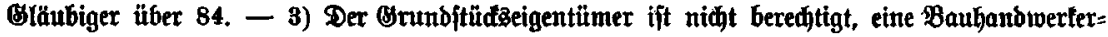
bypothel burd Sidgerheitzleiftung zu bejeitigen 85 .

\section{Miaflerbertrag.} Maflers 87.

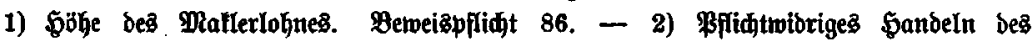

6. $\mathfrak{A}$ uftrag.

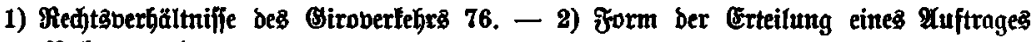
an einen Stedtsammalt 87.

7. Cintringung von Sadien bei Baftritten.

1) Saftung bes Stallwirtes aus bem Bettrage 227. - 2) Waftung Des (Saftrirtes 442. -

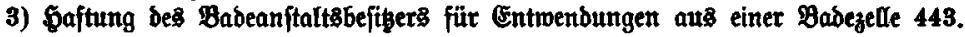

\section{Bejellidaft.}

1) Der wegen einer Bribatjajulb belangte Befellfiafter tann eine Forberung ber Befell=

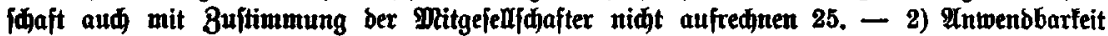

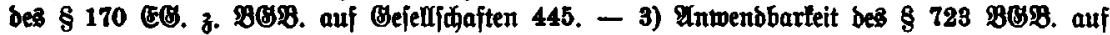

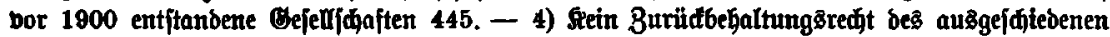
Bejellidafters an bem nod in feiner \$and befindliden Befellidaftabermögen megen nod nidit exfolgter Colbabfinbung 448.

9. Spiel. Bette.

1) Darlelgn zu Spielzmeden 448. - 2) Bedfjel über Spielføulben 448.

\section{Bürgläaft.}

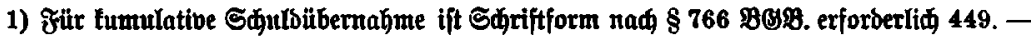
2) Beitbeftimmung bei Bürgfijaften 450. - 3) Stellung bes Bürgen gegenüber eitrer fpäter

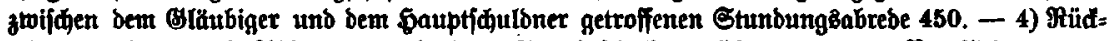
tritt bon ber burd Obtommen mit bem Bemeinjfullbner itbernommenen Berpflidtung zur ubernahme einer פfttorbbürgidaft 453 ,

Begriff bez Bergleidę 8.

$$
\text { 11. Bergleid. }
$$

Ibftraltes Sđulloberfpreden 454.

$$
\text { 12. Sdjulbueripredien. }
$$

13. Ungereditfertigte Bereidferung.

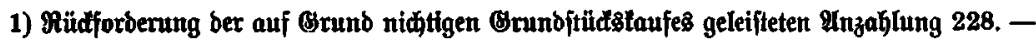

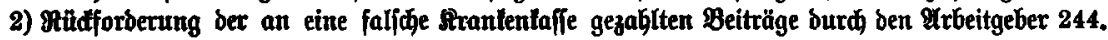

14. Unerlaubte Đandlungen. Anfectung auferthalb des Ronlurjes.

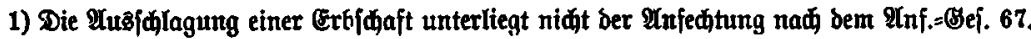

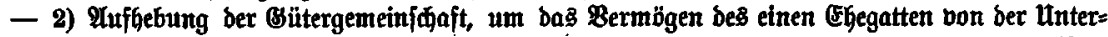

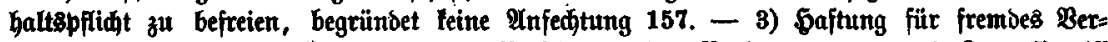
f̈ulben 80. 81. - 4) Sonhurrierendes Beriđulben bes Berlęten 81. - 5) Bum Blegriff

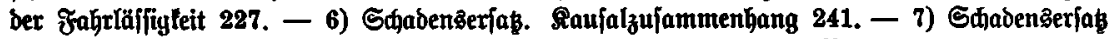

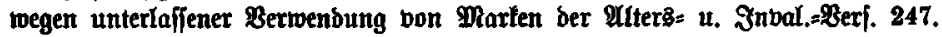

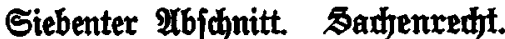

$$
\text { a) Befi ib. }
$$

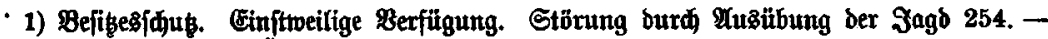

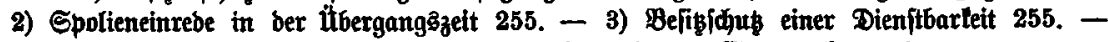

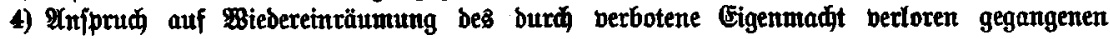
Befitezes 256. 


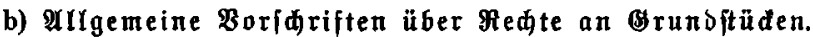

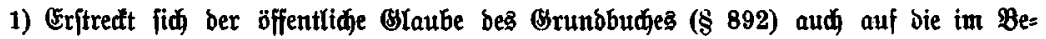

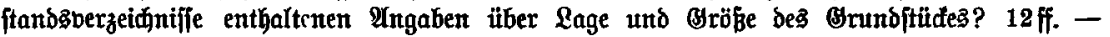

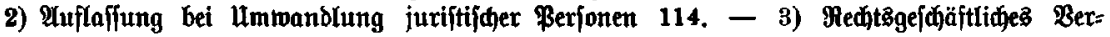

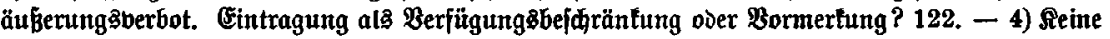

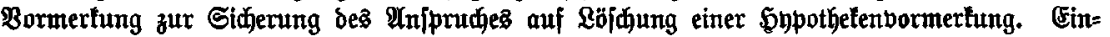

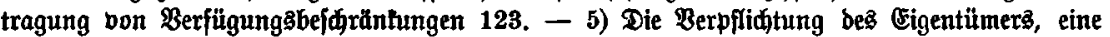

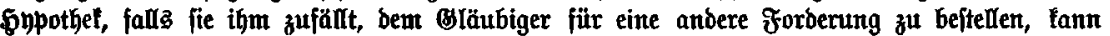
borgemerft werden 150. - 6) Inmieweit beftehen (Exbzingెredfte, Baubejdräntungen uno Ber=

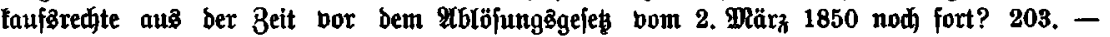

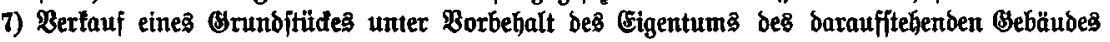

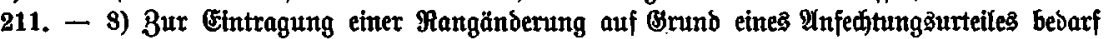

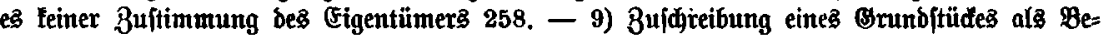
ftanbteil eines anderen 259. - 10) Die Auflafifung allein betwinlt nod nidt bie bezmedte

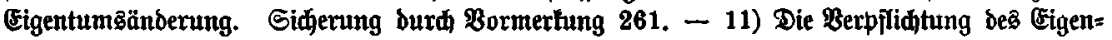

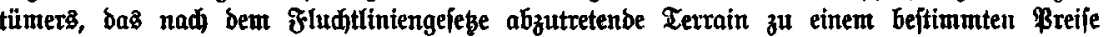

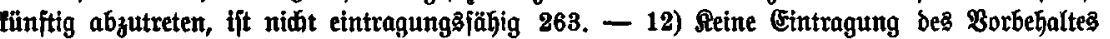

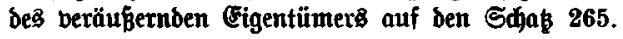

\section{e) Cigentum.}

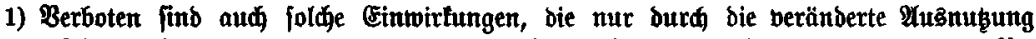

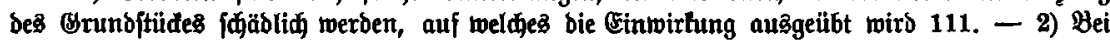

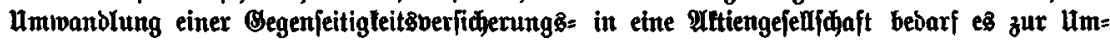

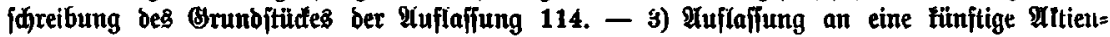
gefellidjajt 486. - 4) Bolizei abliefert, fann fie nidht afs Z̧und ober jonjtivie für fid beanfprudhen 117. - 5) Bor=

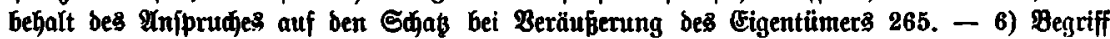

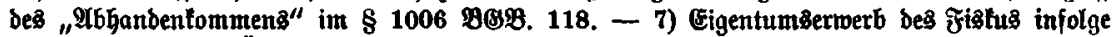

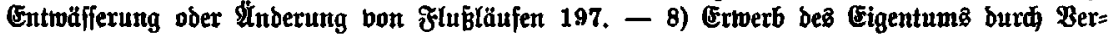

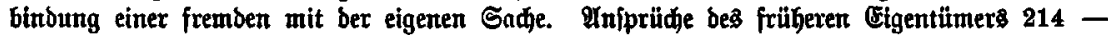

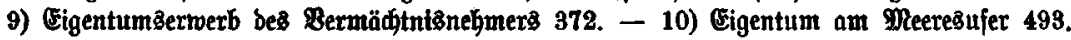

\section{d) Dienftbarteiten.}

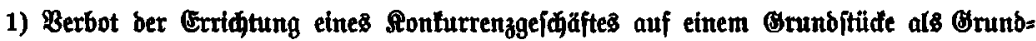

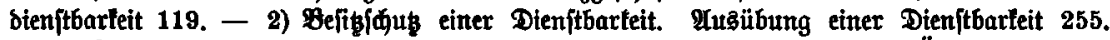

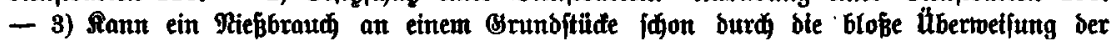

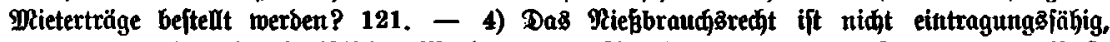
went es mit ben daralteriftif braudi an Spartafienguthaben 267.

\section{e) Supothet.}

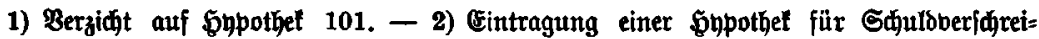

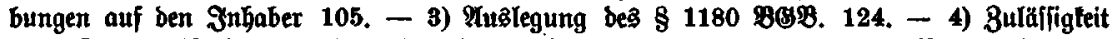
einer Z1wang

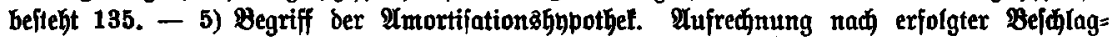

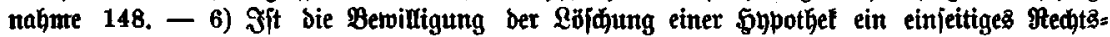

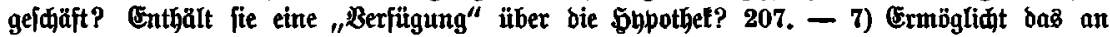
einem Bubehörftü̈d eines Brundftüdtes beftebende gefeglide ßfanbreht bie Begrïnoung eines

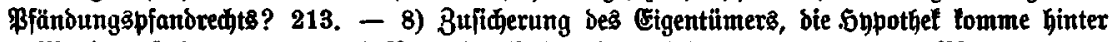
x Mart zu ftehen 269. - 9) Medtşbehelf bes Sypothelengläubigers gegen \$fänòung bon Bubehör 270. - 10) Die Roften einer löjđungosfähtgen Duittung hat ber Eigentümer zu

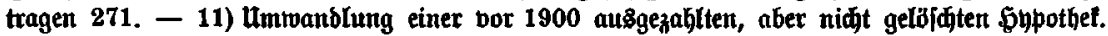

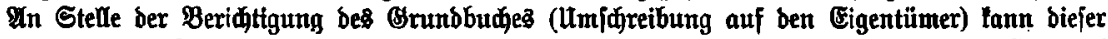

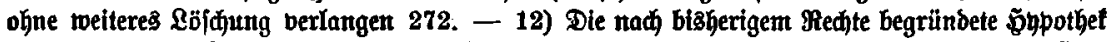

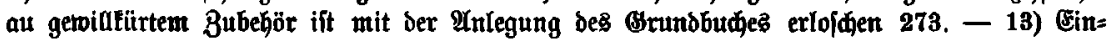

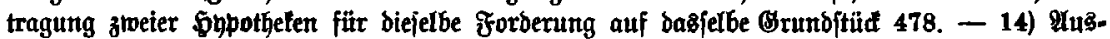




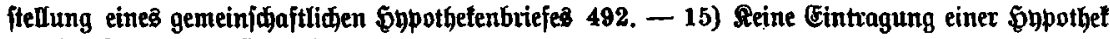
auf bie ZFiruna bes Einzellaufutannes 504.

f) Bfandredt an bewegliden Sadien und Redten.

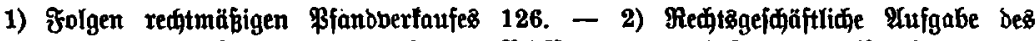

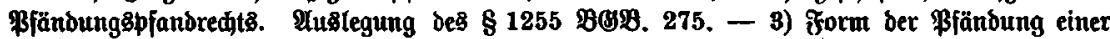
Eigentümergrunofifuld 134. 401. - 4) Berp|änbung eines Spartaffenbudjes 267. - 5) ßfän= bung einer Bormerkutrg alten Fedtes 404.

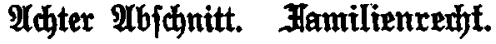

a) Berlöbniz.

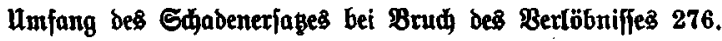

b) 28 ixtung ber EGe im allgemeinen.

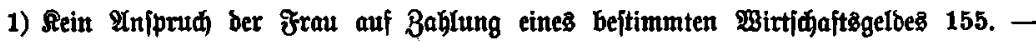
2) Infprud auf Unterfalt gegen ben anderen (Ébegatten 156. - 3) Die zum Betrenntleben

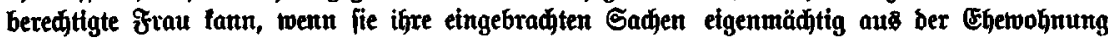

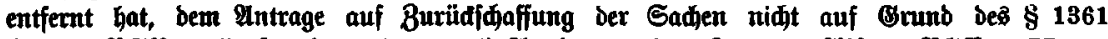

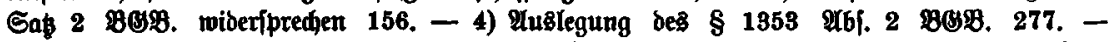

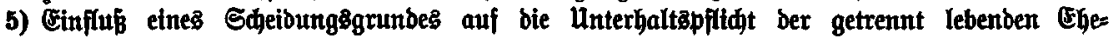
gatten 278.

\section{e) Befęliqe (s) üterredit.}

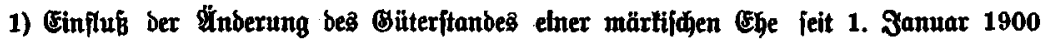
auf ben vorther gemadten Pleingetwinn aud einem bejonberen Bewerbe ber Frau 156 . 2) Enthält bie Bewilligung ber \&öjiqung einer \$apothct eine "Berfügung" über bie \$upothet? Eintwilligung des Eremannes bazu 207.

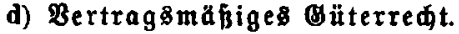

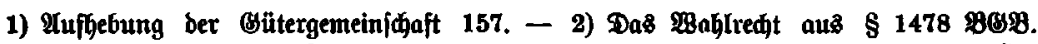
tann geübt werben, folange bie Teilung bes Befantgutes nod nift beendet ift $280 .-3$ ) $C_{r}=$

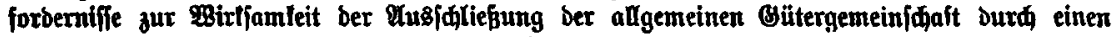
Boutaufmann gegenüber Drttten 158. - 4) Buftimmung ber Frau, wenn ber Mann bei Orntauf

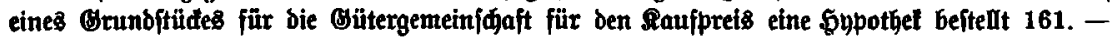

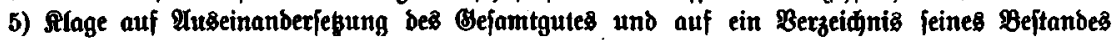

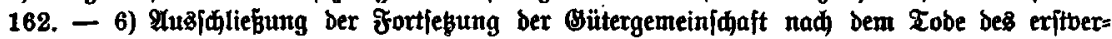

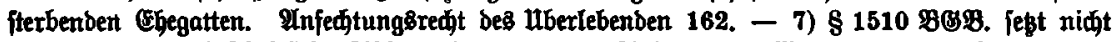

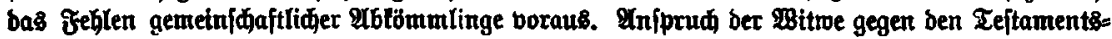

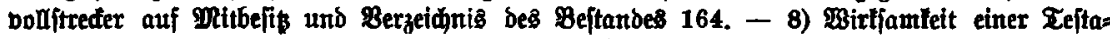

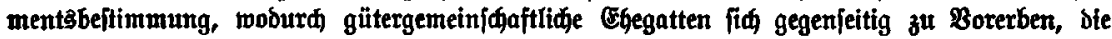

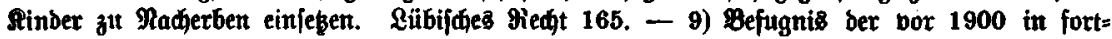

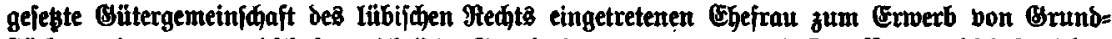

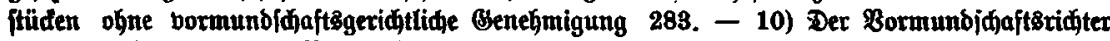

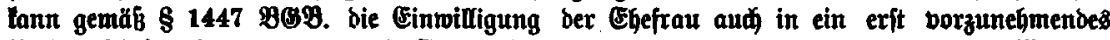

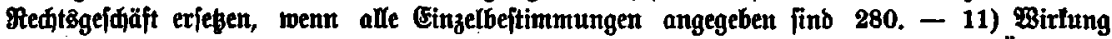

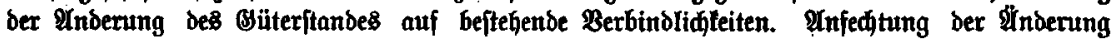

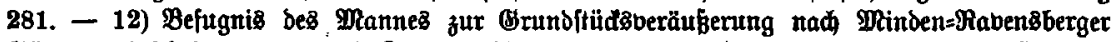

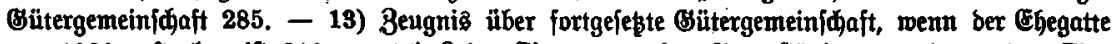

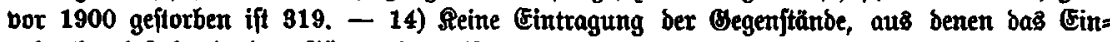

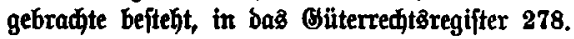

e) Squeidung ber Ehe.

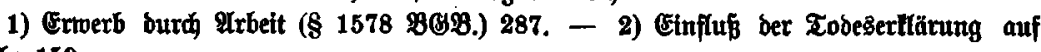
bie cage 153.

f) Bermandtidaft.

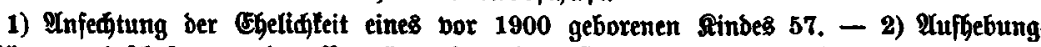

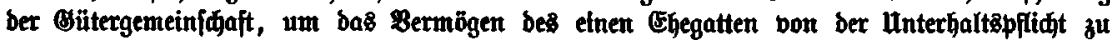




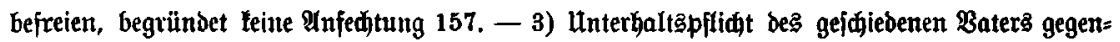

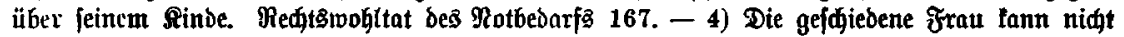

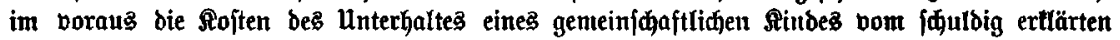

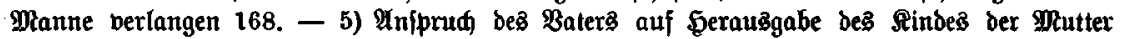

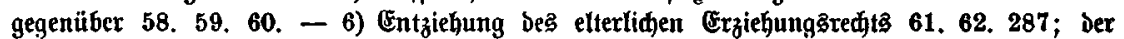
efterliḑen Bewalt 170; wegett unfittliđjen Berbaltens vor Erlangung ber elterliden (Bemalt

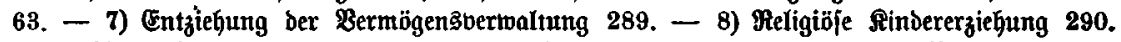

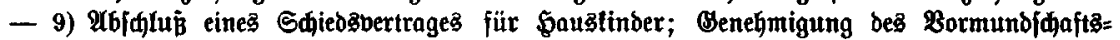

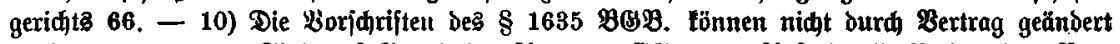

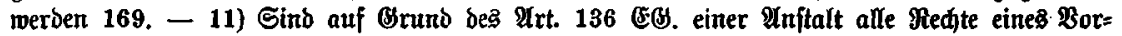
muntbes gegeben, fo hat biefe audf und nidgt bie Mutter bie Sorge für ein unehelidjes Sind

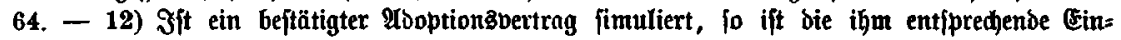
tragung zum beburtąregifter zu lijiđten 289.

g) Bormunofdiaft. Bflegidaft.

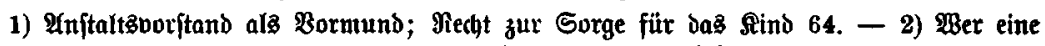

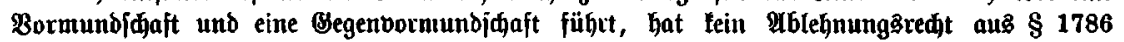

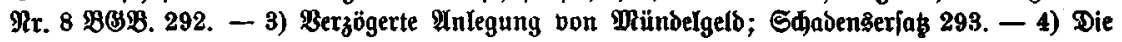
Mitteilung von ber vormumbidaftsggeridtliden Benebmigung ober bon beren Berweigerung ge=

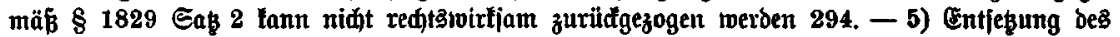
Bemeindebormundes 298. - 6) Bmed ber Bormundidhaft über Brobjährige. Unterbringung

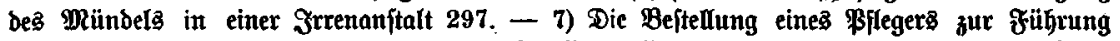

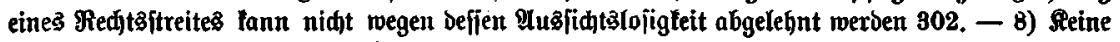

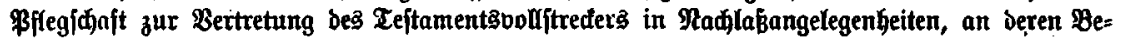

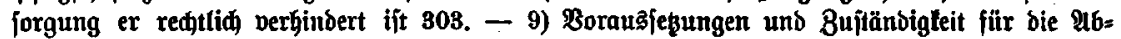

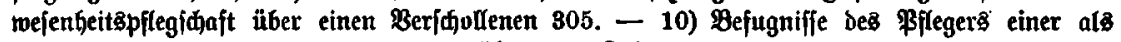

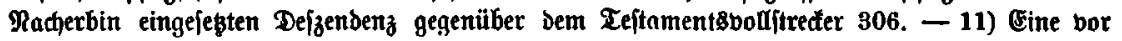
1900 eingeleitete Berwaltung spflegidaft ijt jebt nidt mehr fortzuführen. Befdiegt biez gleid=

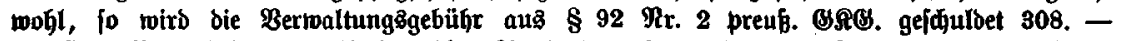

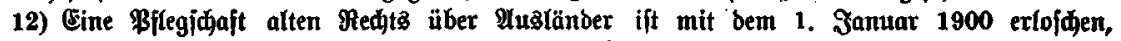

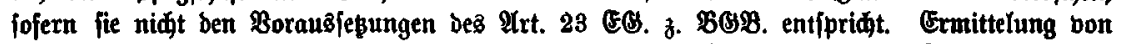

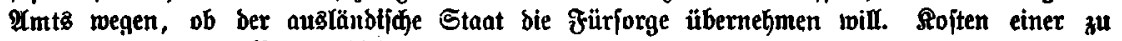
Unredjt fortgejegten Bornumbjiaft 309.

\section{Reuntex $\mathfrak{A} \mathfrak{b}$;}

a) Reథtliळe Stellung bes Erben.

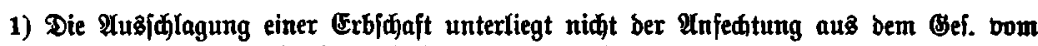

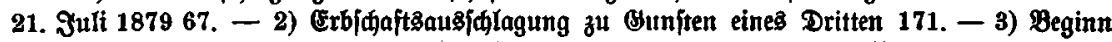

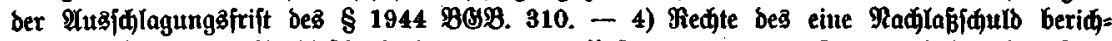
tigenben Erben im Madlaplontur[e 68. - 5) Beftimmung einer Inbentarfifit. Die Frift braudjt mehreren (rben nidt zujammen beftimmt zu merben 70, - 6) Bejdxäntung ber Saftung besె Erben nad erfolgter Teilung bes Madilaffes 172. - 7) Die Inoronung einer

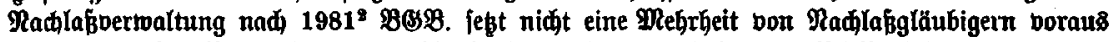

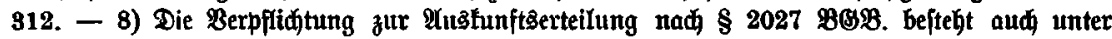
Miterben 314.

\section{b) Teftament.}

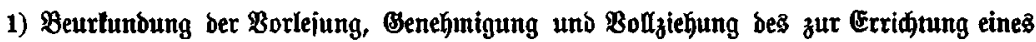
Teftamentes aufgenommenen ßrotofolles burd bie Budjftaben "b. g. u." 20. - 2) Dorf=

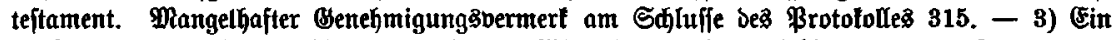

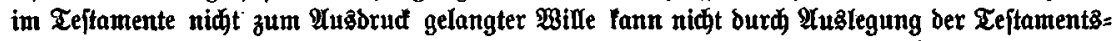

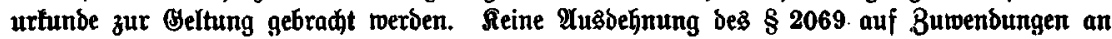
Seitenberwanbte 72. - 4) Anwenoung beą $\$ 2067$ auj älteren Tejtamente. F̧allen unter bie

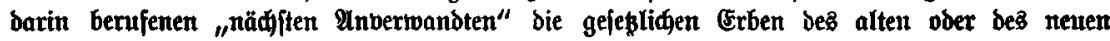

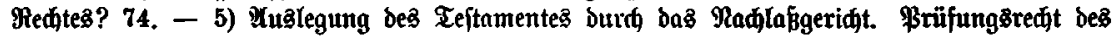




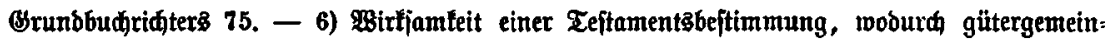

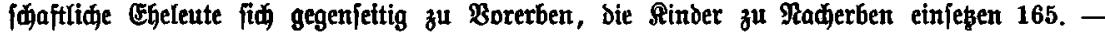

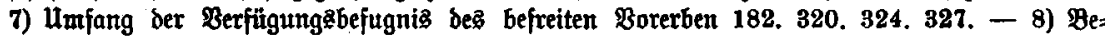

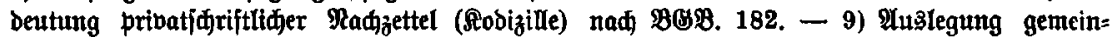

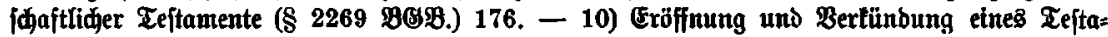
mentes. Inmejentheit bon Beteiligten 179. - 11) Reine \$Pflegfdaft zur Bertreturg bes

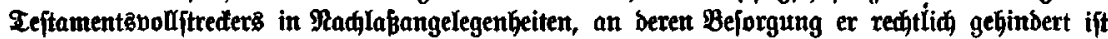

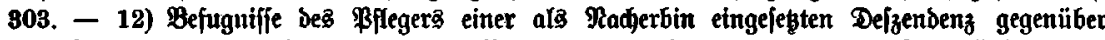

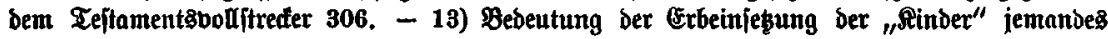

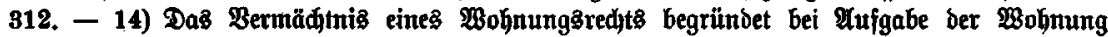

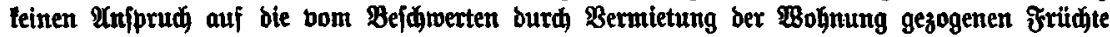

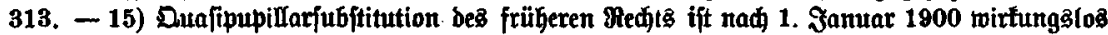

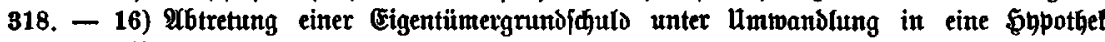
burm Dent ßorerben 327.

c) Erbbertrag.

Unfedtung eines bor 1900 erridfteten Crbbertrages wegen eines nadher entitandenen \$fliditteiläbereditigten 338.

d) Bflidtteil.

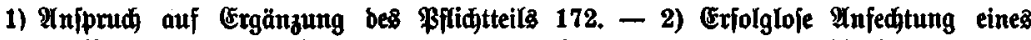

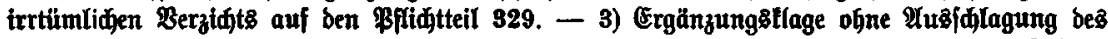
Ginterlaffenen Erbteils. F̧amilienftiftungen = und fibeitommiffe als "Shentungen an Dritte"

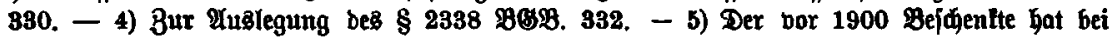

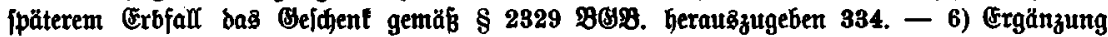

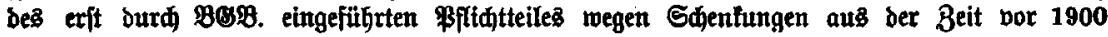

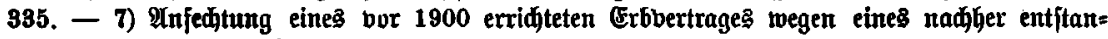
benen \$Flidtteilsberedtigten 338.

e) Erbjaeitr.

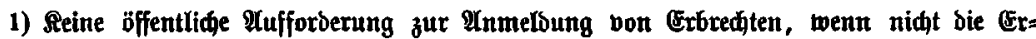
teilung einesి Erbjđeines beantragt wiro. Erforbernifije biejes Antrages 174. - 2) Begen=

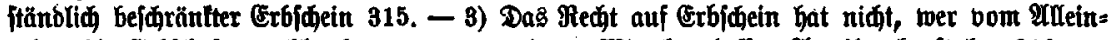
erben bie (Erbijaft, wohl aber, wer bon einem Miterben beffen $\mathfrak{A n t e i l}$ gefauft hat 316. -

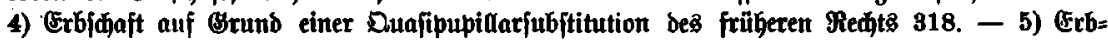
beidheinigung und Beugnis über fortgefepte Bütergemeinfdafaft, wenn ber EGegatte bor dem

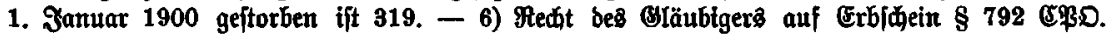

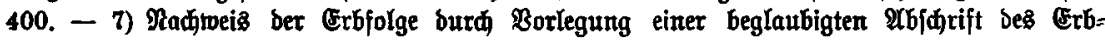
iqueines 479.

\section{Behnter श्Abjdnitt.}

a) Der Raufmann.

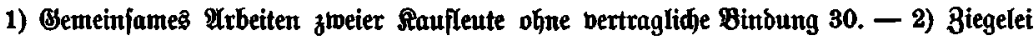

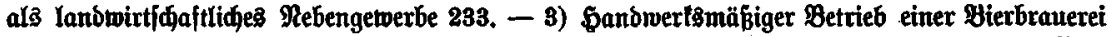
234. - 4) Begriff bes Rleingewerbes (Baftwirtfáaft) 466. - 5) Beneralagent bon Ber=

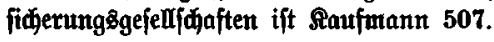

\section{b) Die Sandelsfirma.}

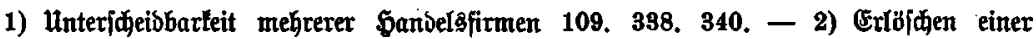

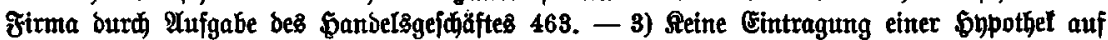
bie Firma bes Einzelfaufmannes 504.

c) Sanbeloregititer.

1) Bulaffigleit einer Rlage auf Betwiligung einer Röjđung im \$tegifter 37. - 2) Ein=

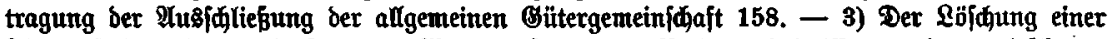

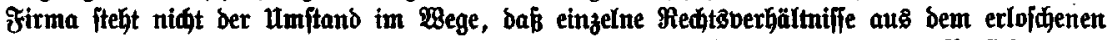

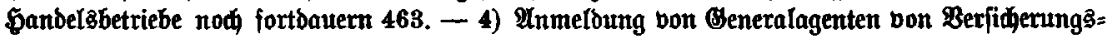
aftiengejellfifiaften $\mathbf{5 0 7}$. 


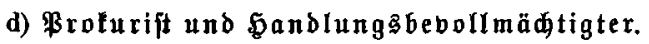

1) Beiđränlung ber Bertretungşınađt bez \$roluriften auf bie bauptniederlaffung unter

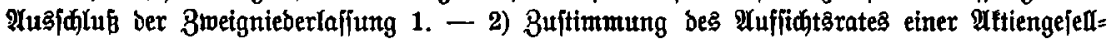
id̆aft zur Erteilung Der \$rohura. 1. Anm. - 3) Die (Ermädhtigung deş Brofuriftent zur Bèlajturtg und Beräußerung bon Brunoftïđen tann ins GandelBregifter eingetragen merben 186.

e) Sanblungagehilfen und =lehrlinge.

1) $\mathfrak{B e m}$ geh̆̈ren bie Ergebniffe ber Erfindertätigleit eineß $\mathfrak{A n g e j t e l l t e n ? ~ 2 . ~ - ~ 2 ) ~ E n t = ~}$

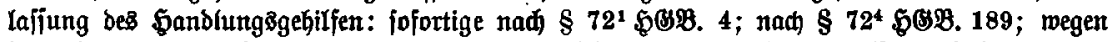

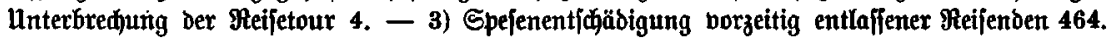

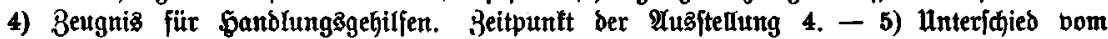
Getwerbegehilfen 348. - 6) Burüdbehaltungäredt bes Sanolungäreifenden an ser Mufter= fammlung tea ßrinzipals 350.

f) Sandrungzagent.

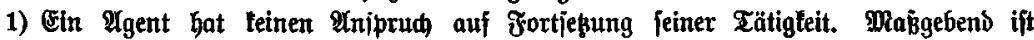

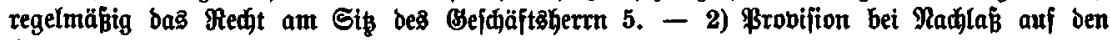

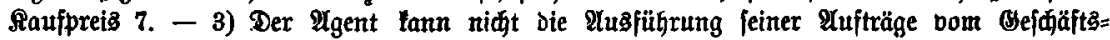
herrn berlangen 189.

g) Dffene \$andelsgeferlfdaft.

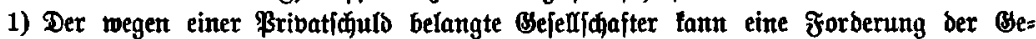

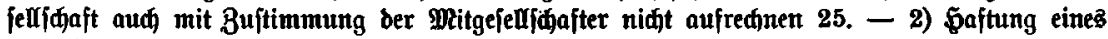

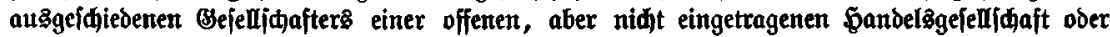

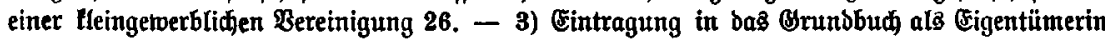

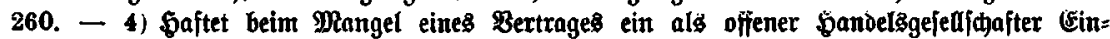

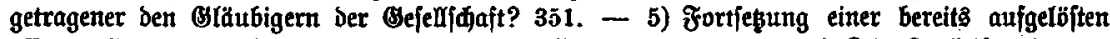

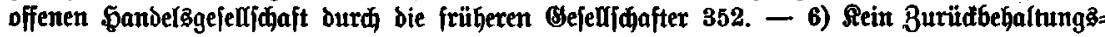

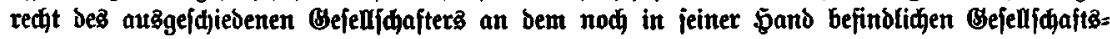

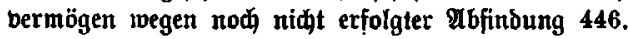

\section{h) Altiengefellidaft.}

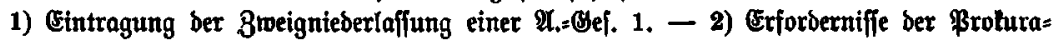

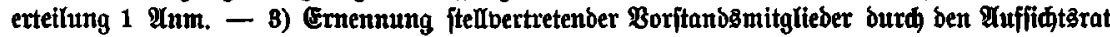

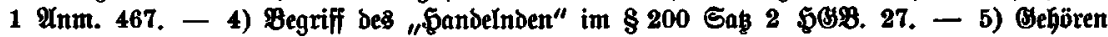
bie auf Brunb vont Dibibendengarantien von Dritten gezablten Beträge zum Reingeminn? Sit bon ihnen $1 / 20$ in ben Bilanz=-Mejerbefonds einjuftellen? 28. - 6) Begenüber einer

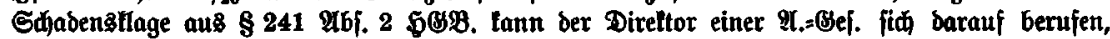

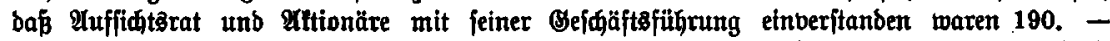

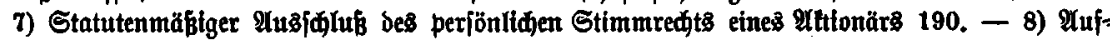

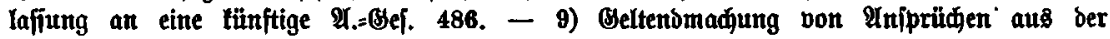
Bründung burw bie Minderbeit. Winterlegung bon $\mathfrak{A}$ (ttien 508.

i) Befellífaft m. b. 5.

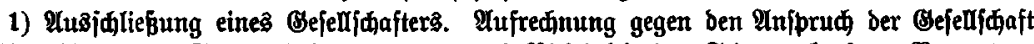
auf Einzahlung ber Stammeinlage 191. - 2) Plidtigfeit bes Stimmentaufeas. Borbertrag

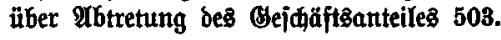

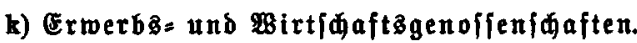

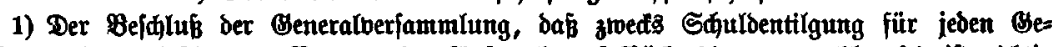

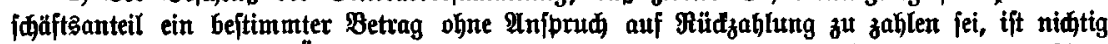

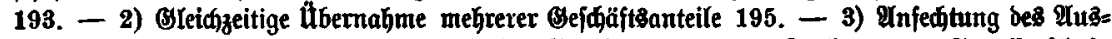

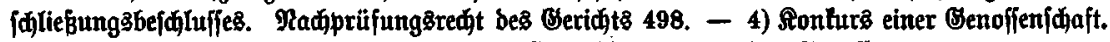
Anttellung des Borftantes. Fortbauer der Einzaflungspflidt ber Benoffen 500 .

1) Bon ben Đanbelogefdăften.

1. İm allgemeinen.

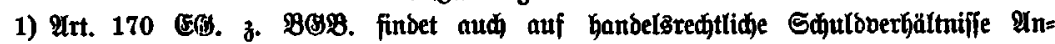

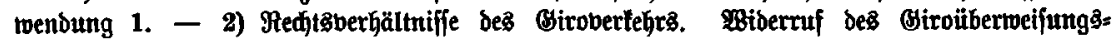




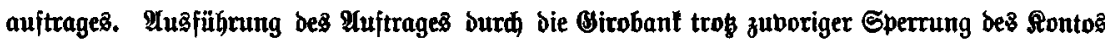

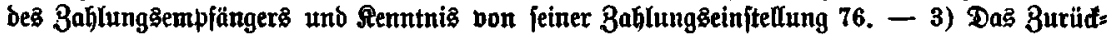

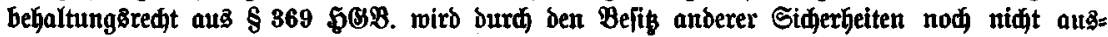

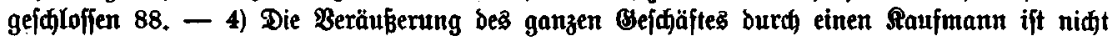

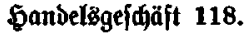

\section{2. Бandeläłauf.}

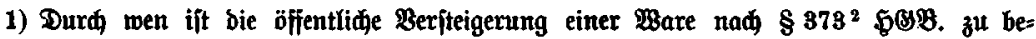

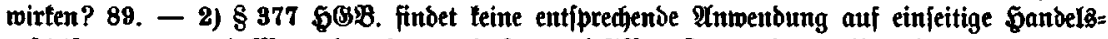

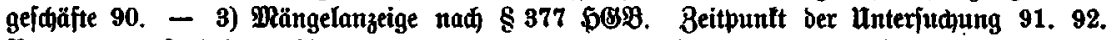

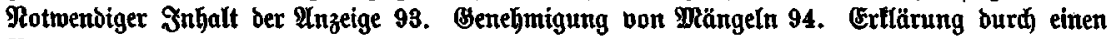
Bertreter 224. - 4) Die für einen Gelffthilfebertauf erforberlide Snoibibualifierung bex

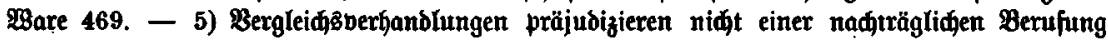

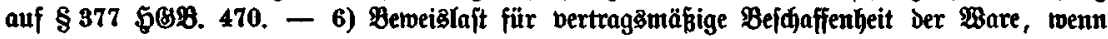

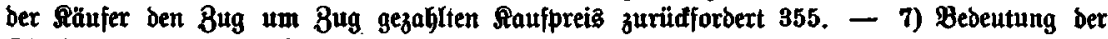

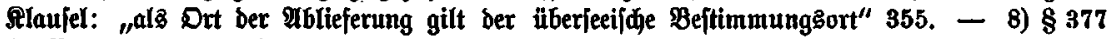

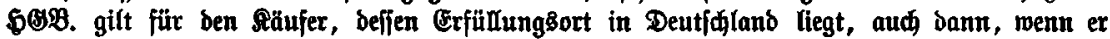
Śjabenserjaß wegen mangelhafter Rieferung forbert 355. - 9) Sadmiete im Betreibe= hanbel 356.

\section{Sommiffiongెgeiđäft.}

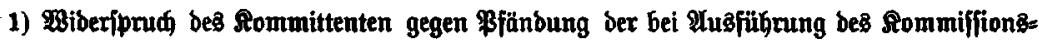

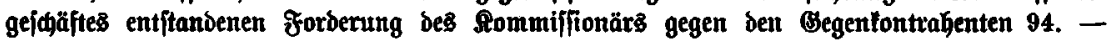

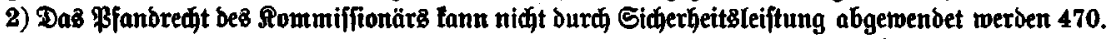

4) Spebitionşgejfäät. blättern 95.

Sit Innoncenbureau Sommiffions= ober Spebition\&gejđäft? Sieferung bon Beleg=

\section{5. Żradtgejăft.}

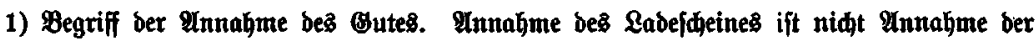

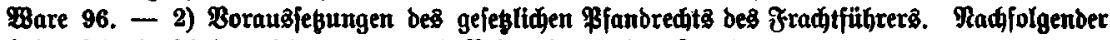

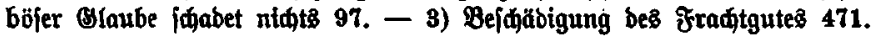

\section{Seebandel und Binnenjaiffabrt.}

1) Rein $\mathfrak{A} \mathfrak{n}$ prumb auf Lieferung bon $\mathfrak{B}$ aren mit ber im Ronnofiement angegebenen

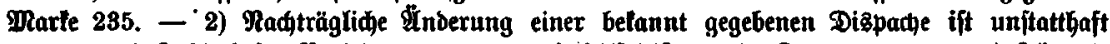
357. - 3) Zeblerbafte Berlabung 357. - 4) Gilfeleiftung in Seenot 357. - 5) Für bie

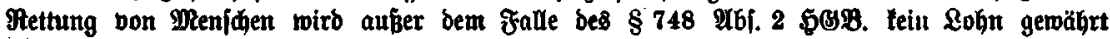

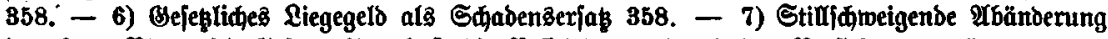

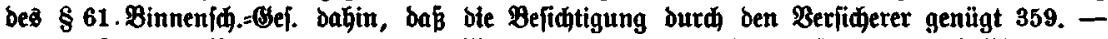

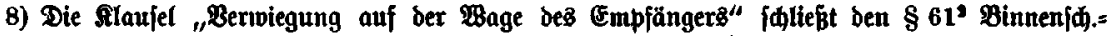

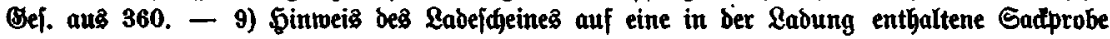

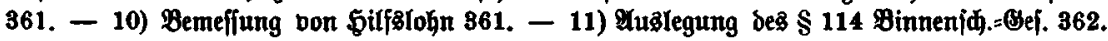

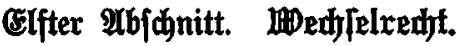

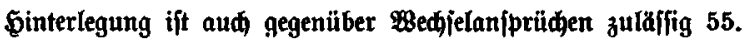

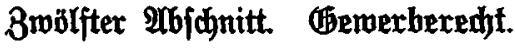

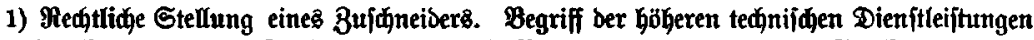

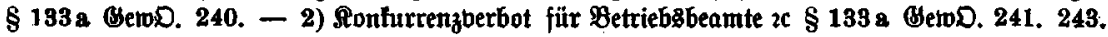

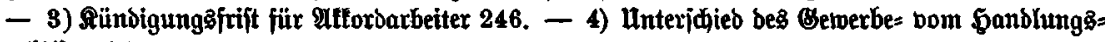
gefilfen 348.

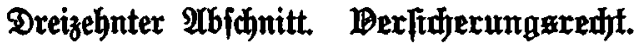

1) Berpflidtung bes auf Begenteitigfeit Berfidjerten, Umlagen und Differenzprämien zu bezablen 248. - 2) Berfiderung gegen unfall: a) Offenbare Srunfenheit. Beweislajt 249; 


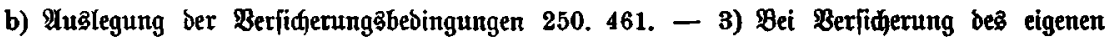

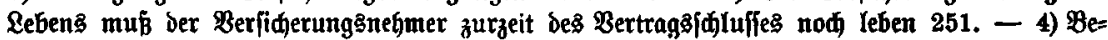

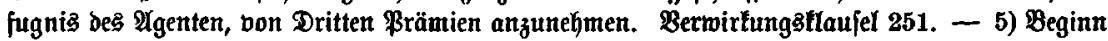

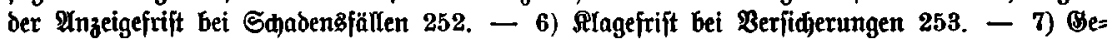

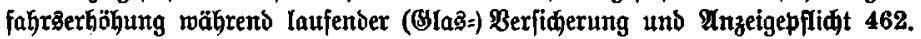

\section{Biezzehnter $\mathfrak{A b}$ fdnitt. Jitheiternerftuterumgeredt.}

a) Rrantenberfi

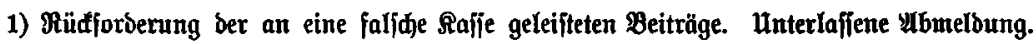
Buftänbigteit ber Behörben bei Streitigleit, weldhe ßafie zuftänbig ift 244. - 2) Frreimillige

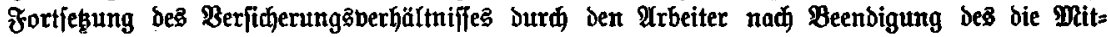

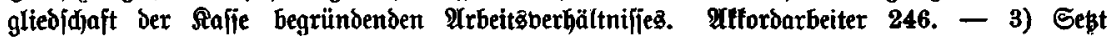

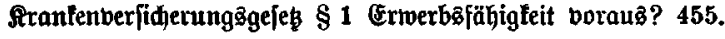

b) Эnbalibenberfiderung.

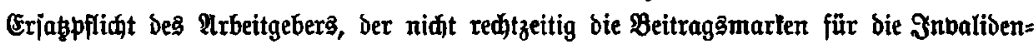
verficherung eingeftebt hat 247.

c) $\mathfrak{u}$ fallberji旡erung.

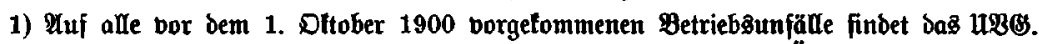

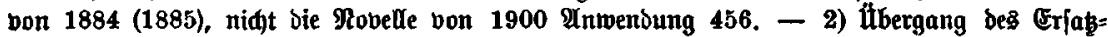

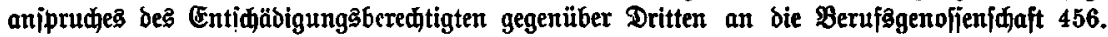

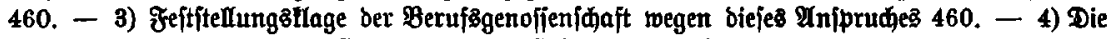

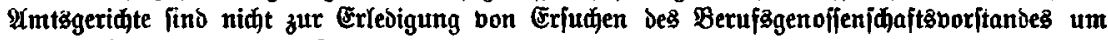
eidlide Bernefimung bon Beugen berpflidtet 494.

\section{Freiwillige (beridhtsbarkeit.}

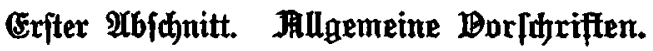

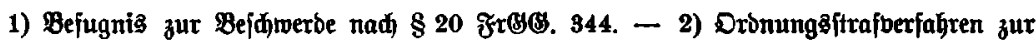

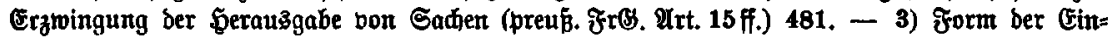

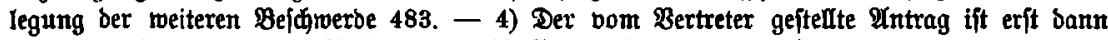

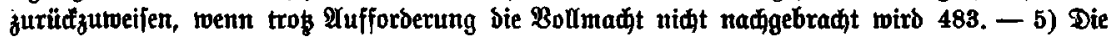

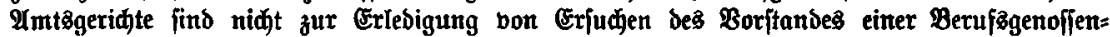

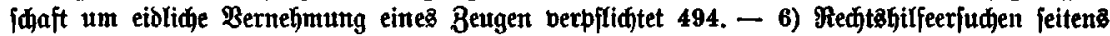

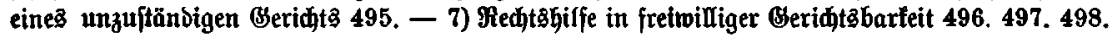

\section{3reiter $\mathfrak{2}$ bjd}

1) Eintragung Der (Sejamtgutsteilhaber als Eigentümer eines (runditüđes 11. - 2) Ein

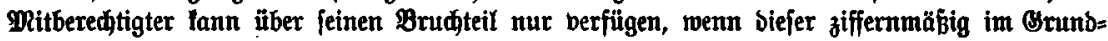

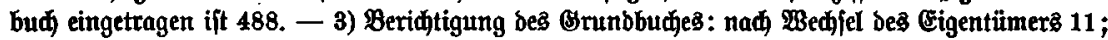

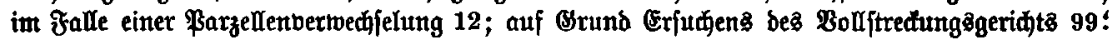

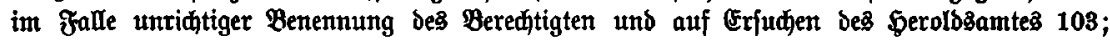

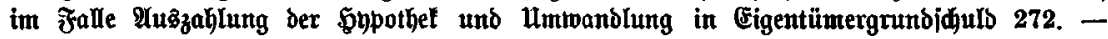

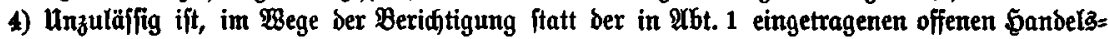

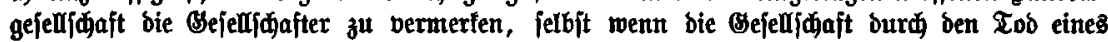
(Bejellfinaftera aufgelöft ift 260. - 5) Eintragung auf Brund Erjuthens von Beförben: bes

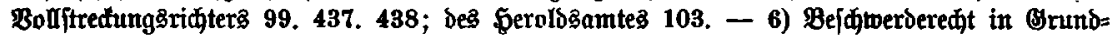

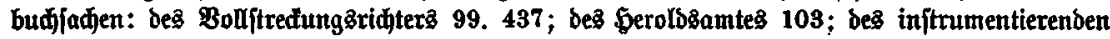
Motars 196. - 7) a) Botlegung eines (Erbidfeines neben Teitament $x$ 15; b) Radiprïfung

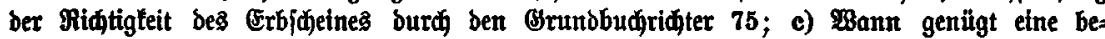

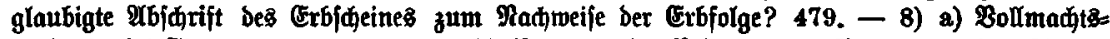

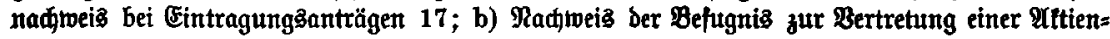




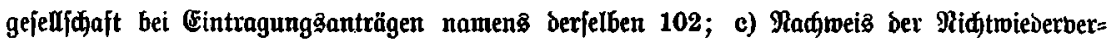

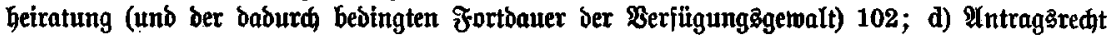

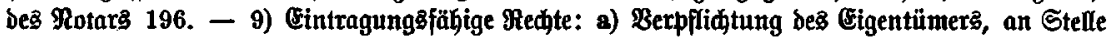

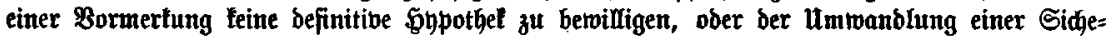

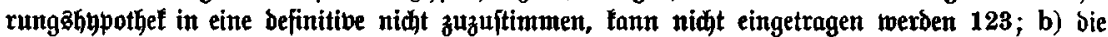

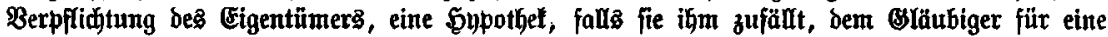
andere Forberung zu beftellen, fann borgemerft werben 150; c) bie Berpflidtung bes (cigen=

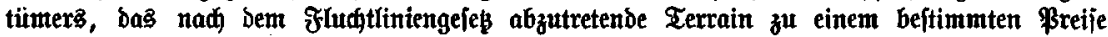

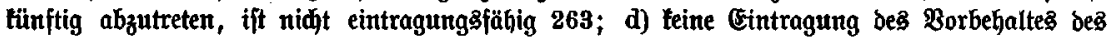

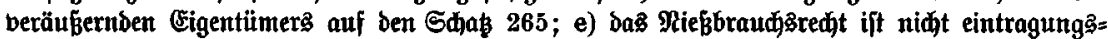

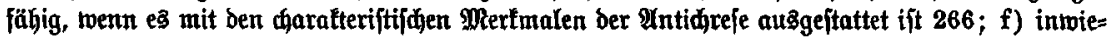

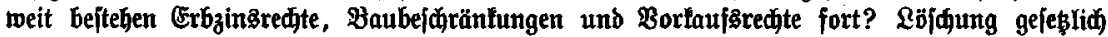

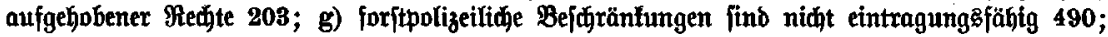

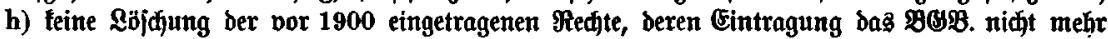

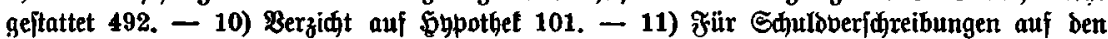

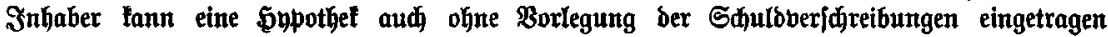

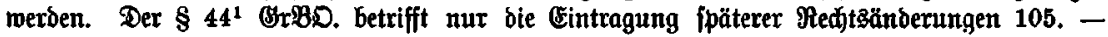

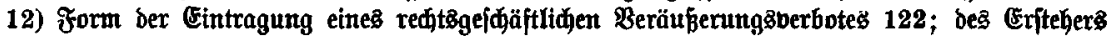

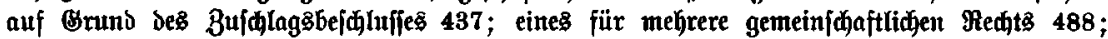
ber Unterwerfung unter fofortige Bwangsooliftređung 407. - 13) Buläfifigfeit einer Bwangs: neben Bertragąfypothet 135. - 14) Eintragung zweier Eypothelen für biefelbe łrorberung auf

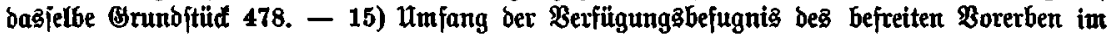

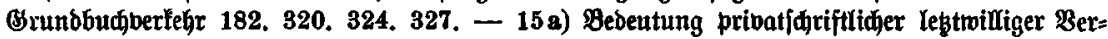

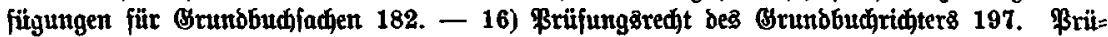

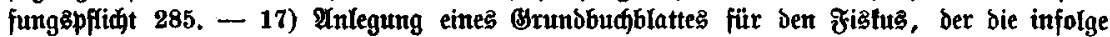

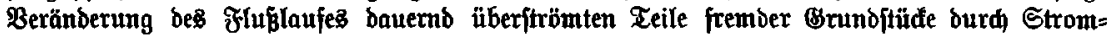
regulierung trođen legte 197. - 18) Die Landesbireltoren find teine ftatlichen Behörben im

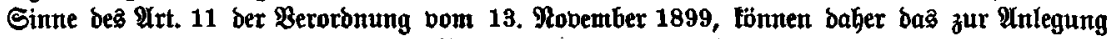

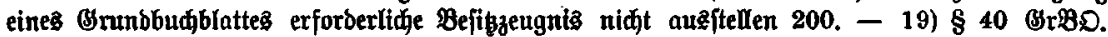

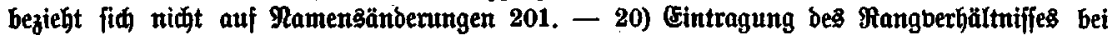

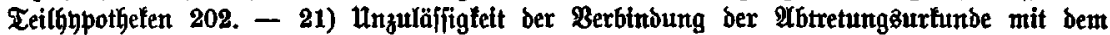

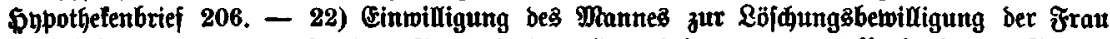

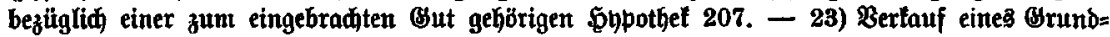
ftüdes unter Borbehalt bes Eigentumes des darauf ftehenden (jebäudes 211. - 24) Bur

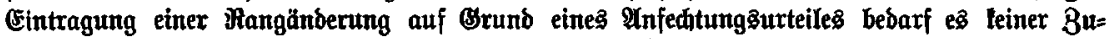

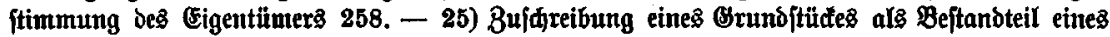

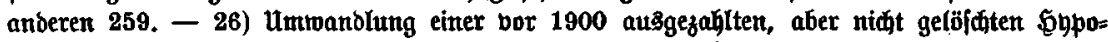

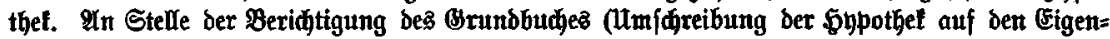

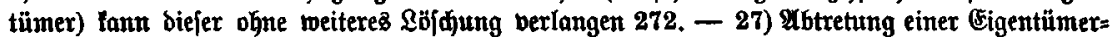

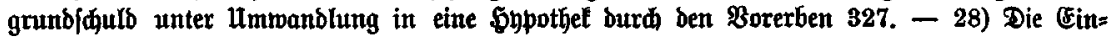

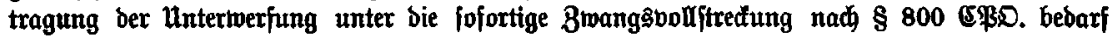

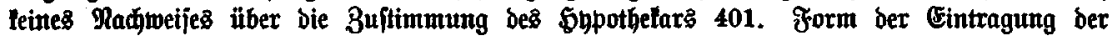

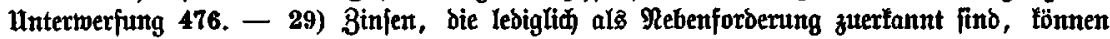
nid)t als felbftänbige pauptforderung eingetragen werden 407. - 30) Den 2 (ntrag auf $\mathscr{U}$ uf $=$

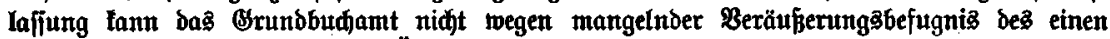

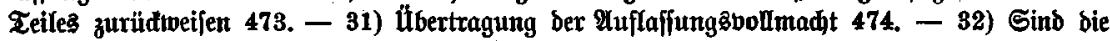
Grben befannt, fo find Cinträge im Srundbude auf beren Ramen zu bemirfen. Bermert ber

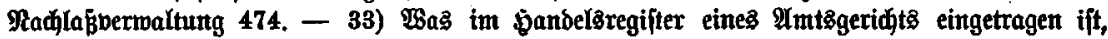

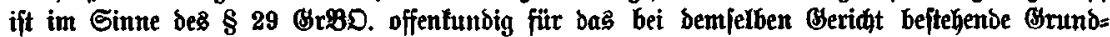
buthamt 475. - 34) (Eintragungaberwilligung mit Borbehalt ber Benehmigung 477. 35) Bültigfeit einer an bie tünftige Altiengefelfinaft bewirtten \&uflaffung feitend eines ein

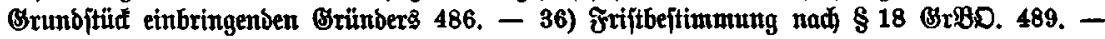

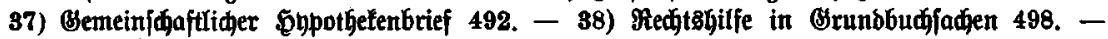
39) Eintragung einer bypotfel auf bie Firma bes Einzelfaufmanness 504. 


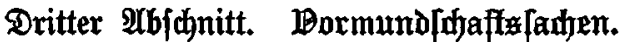

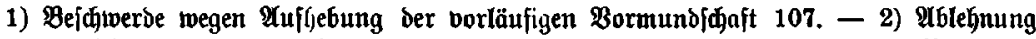

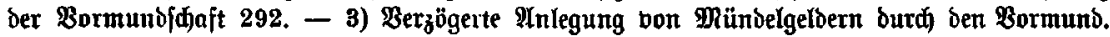

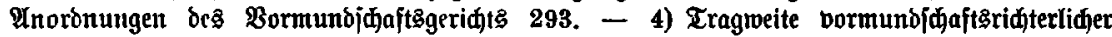
Aftennotizen und unter genehmigungąpflictige (Erflärungen gefeģter Bifabermerfe 296. 5) Entfetzung Des Bemeindebormundes. Beidwerderedht bes Bürgermeifters 298. - 6) Be=

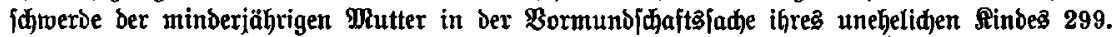

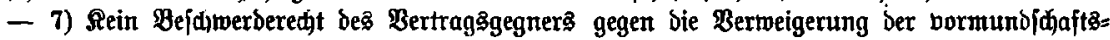

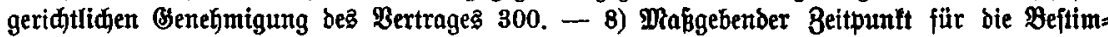

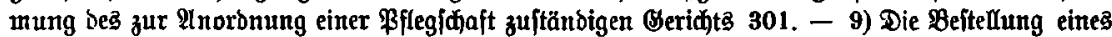

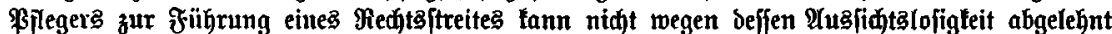

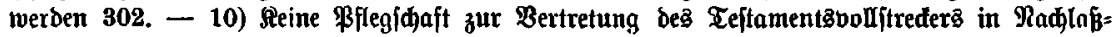
angelegentheiten, an beren Bejorgung er redtlid verhindert ift 303. - 11) Boraubiję̧ungen

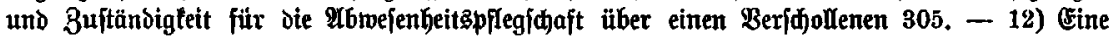

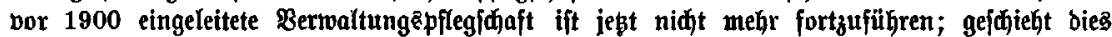

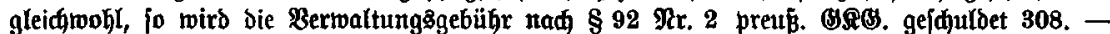

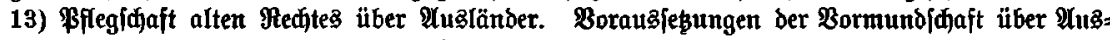

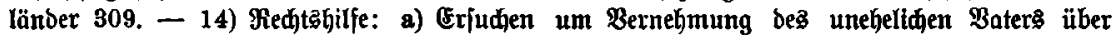

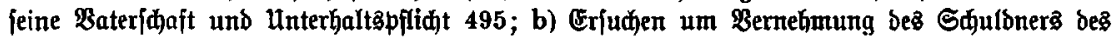
Miindels 496.

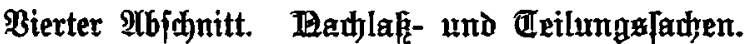

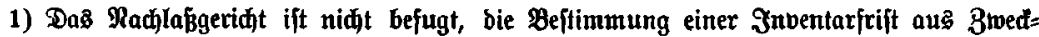

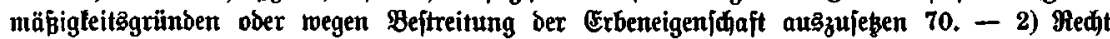

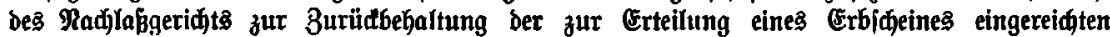
Berfonenf́tandäurhunden 175. - 3) Begriff Der Eröffnung und Form Der Berliünoung eines Teftamentes 179. - 4) itber die Berpfliçtung zut Reiftung bes Dffenbarungseides nah) \$ 79

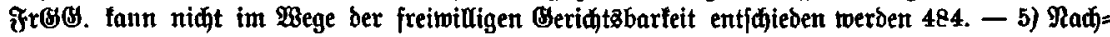
Iaß̧teilungesperfahren. Behanblung bon Streitpuntten 484. - 6) Sit ein Teilungäberfahren boljtänbig abgeiflofjen, fo lann, weil Saden beridjwiegen find, nidt ein neues Berfahren eingeleitet, forbern nur bas alte angeforten werben $\mathbf{4 8 6}$.

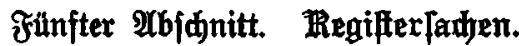

a) Standeşregifter.

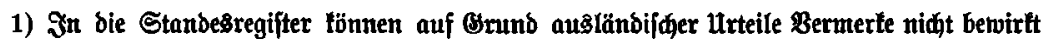

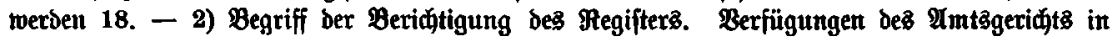

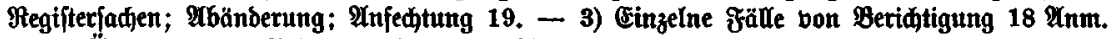

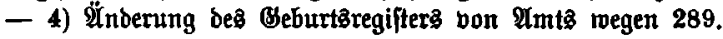

\section{b) Sandelsregifter.}

1) Die Eintragung der Bweignieberlafiung einer $\mathfrak{A} .=$ Bef. Darf nifit bon einer bie $\mathfrak{B r o}=$ huren betreffendent (Eintragung in baş Đauptregifter abhängig gemađt merben 1. - 2) Eint=

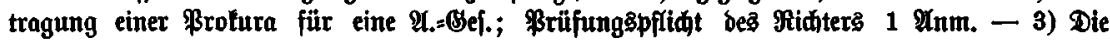
Plusbefgnung ber Brofura auf bie Berfügung über Brumbitüđfe tann eingetragen merben 186.

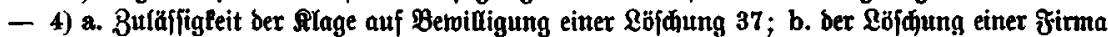

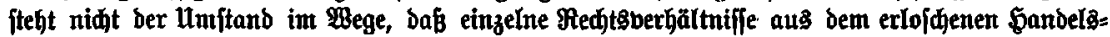
betriebe nod fortbauern 463, - 5) Eintragungaspflithtige Betriebe: Biegelei 233; Brauterei

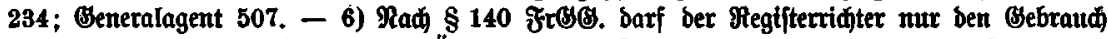

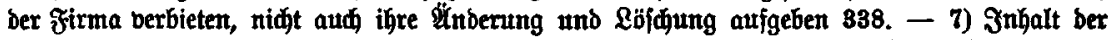
bas Berfabren auf Qb̈|duntg einer Žirma einteitenden Berfügung. Beine Unterjagung etnzelner Teile ber Firma $\mathbf{9 4 0}$. 


\section{c) Büterredt}

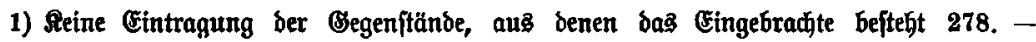
2) Erforberniffe Deß $\mathscr{A}$ ntrages eines Notars auf Eintragung eines Ehebertrages in bas (Süter= rechtsiregiifter 286.

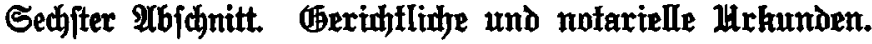

1) Beurfundung Der Borlejung, Bentehmigung und Bollziełung eines Protofolls surch bie Pudjitaben "b. g. u." 20. - 2) Benebmigungäbermerf unter einem eir Seftament enthalten=

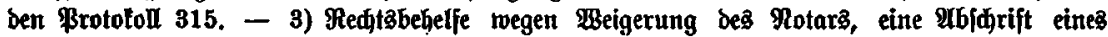
bon ing über eine Beneral=(Bemerfens)Berjammlung geführten \$rototolls zu erteilen 23. 4) Blą der Unteridrift unter ein \$rototoll 108. - 5) Die geridtlidje Beglaubigung lann

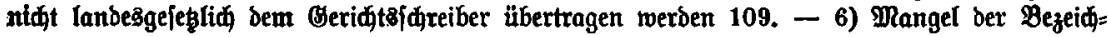

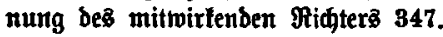

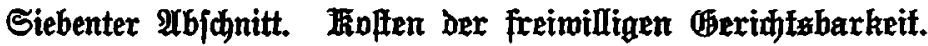
Beugengebühljen.

1) Bur Entfajelbung über bie weitere \$eidwerbe wegen Beugengebühren ift bas Sammer=

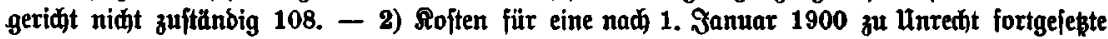

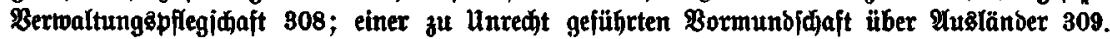

\section{Civilprozeß.}

\section{(5xjtex Ibjanitt. Tie (bexidfte.}

a) Beriditstand.

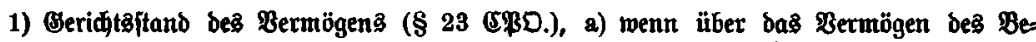

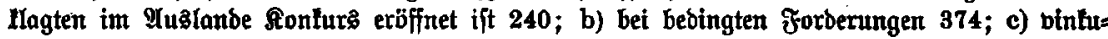

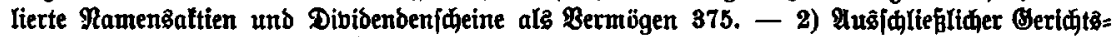

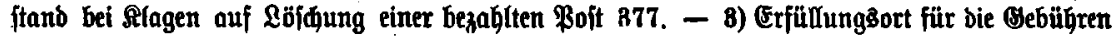

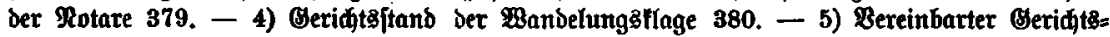

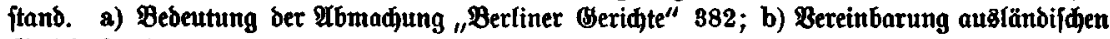
Beriatsftatides $\mathbf{3 8 4}$.

\section{b) Bert bes Streitgegenftandes.}

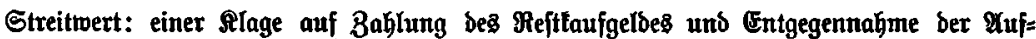

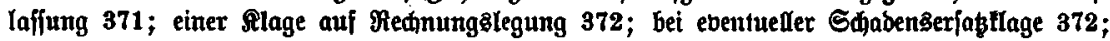

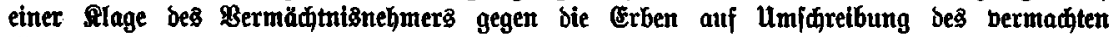

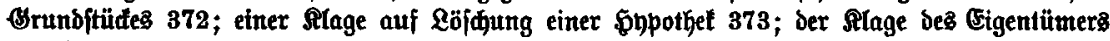

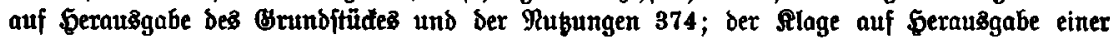
Rebenzberfidjerungßpoltce an ben Berifderten $\mathbf{3 7 4}$.

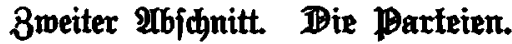

a) Saupt $=$ und Rebeninterbention.

(Eintritt des Semeinjđulbners in ben \$rozés 396.

b) Brozębebollmädtigte.

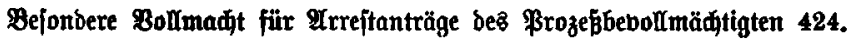

c) Frozébloften im allgemeinen.

1) Eritattung Der Rojten einer vorangegangenen Betweisfiderung 384. - 2) Die ben

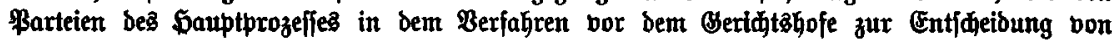
- Rompetenzlonfliften entftandenen Roften find erftattungajpähig 385. - 3) Roftentragung, wenn

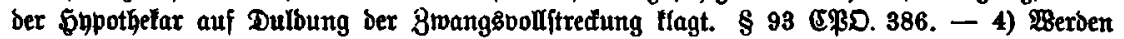
nad Cinreidung ber STagidrift Sapital und Binfen bezablt, io tann bod bie Buftellung 
wegen ber Roften erfolgen 387. - 5) Umfaft ein B̉ergleid weitere al3 bie im Brozeffe

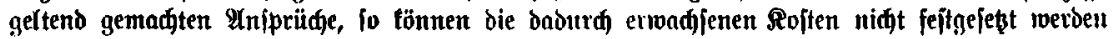

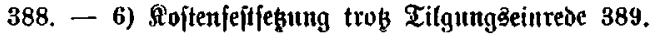

\section{d) Armenredt.}

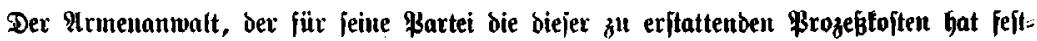

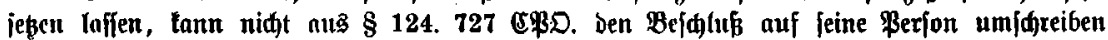
Iafient 130.

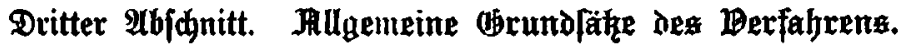

a) Buitellungen.

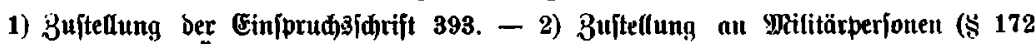

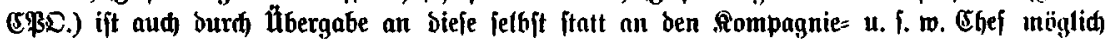

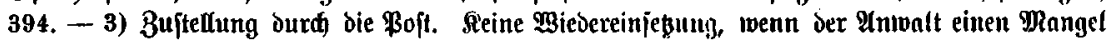
Der Buftenlung überjegen hat 394.

b) Sadungen. Termilte. Friften.

3it die Bartei an bem nach $\$ 141$ amgeoroneten perjönlidhen Erjdeinen burdh \$rantbeit verbinoert, fo ift ein Termin an Drt unb Stefle nidt nad) \$249 "erforberlid" 391.

c) Bolge» ber Beriäumung. Biebereinfebuug.

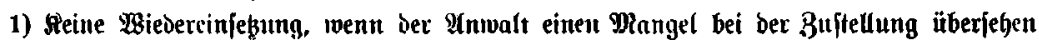
fat 394. - 2) Beredgung Der 2 Biedereinjeßungafrift 395.

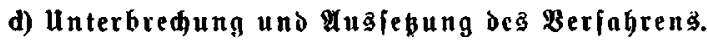

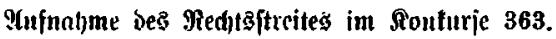

\section{Bierter $\mathfrak{A b j}$ bnitt. Berfahren in erfter Inftan.}

a) Rlagerbebung.

Beftimmthrit beş Ragantrages 397.

b) Feftitellungstlage.

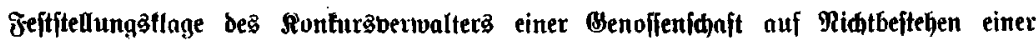

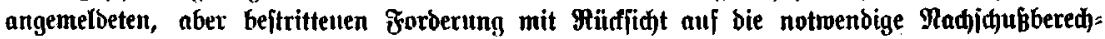
nung 239.

c) Enburteil. Teilurteil. Bwifdenurteil. Fedtatraft.

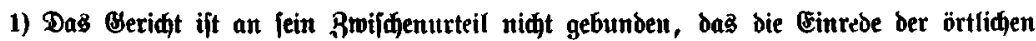

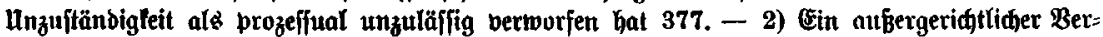

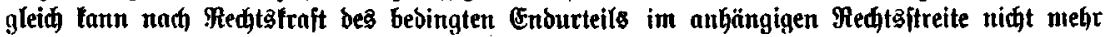
geftend gemadt werben 398. - 3) Mirfing ber Mecht3fraft im Faffe bes \$ 471 ERD. 398.

- 4) Einmenoungen gegent redtsträftiges Urteil 399.

Beglaubigung der (Einfiprudisfidrift 393.

$$
\text { d) Berfäumnisutreil. }
$$

\section{e) Beugenbemeis.}

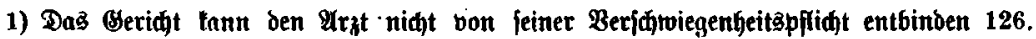
- 2) Ilmfang des Bengnizbermeigerungşredta cea Motars 128.

\section{f) Beweis burd Eid.}

Tod des Ed)murpflidtigen nud Erlás desి bedingten Enourteils 398.

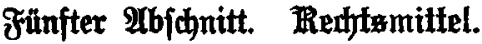

a) Befthrorbe. buabe 143

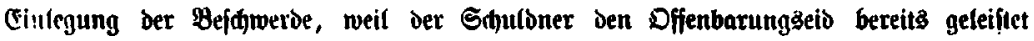


b) Berufung.

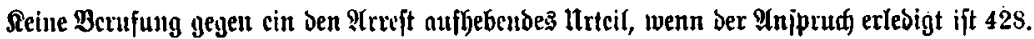

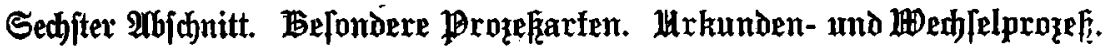

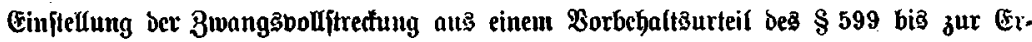

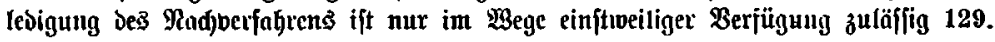

\section{Siebenter $\mathfrak{A b j a n i t t . ~ B w a n g a n d l f t r e d a m y . ~}$}

a) Alfgencinc Beftimnungen.

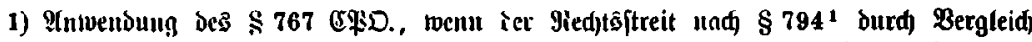

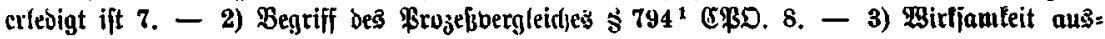

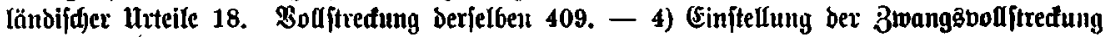

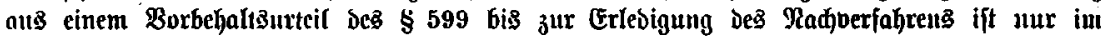

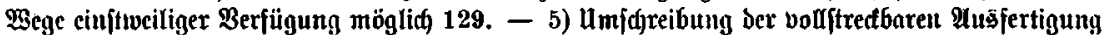
nuf Den Medtsunadfolger 130. - 6) Bodftredbarteit eines in cerlebigung einer beantragten

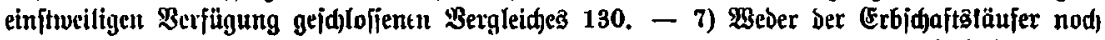

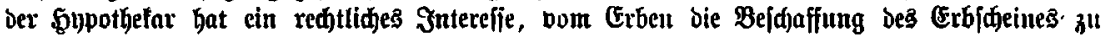
verlangen 400. - 8) Die Eintragung Der llnteriverfung unter bie fofortige Bivangşoolftrefung

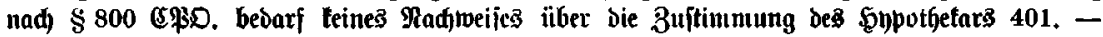

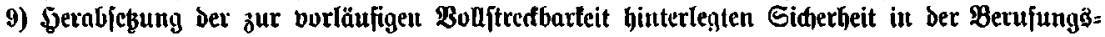

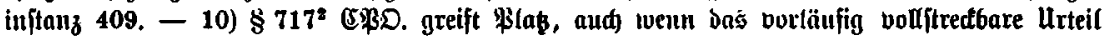

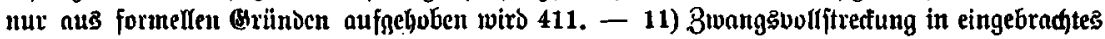

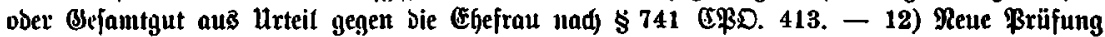

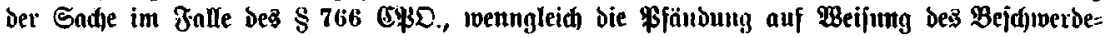
getid)!3 exfolgte 421 .

\section{b) Einfprud britter Werjonen.}

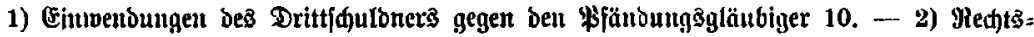

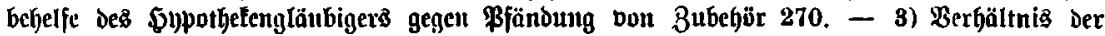

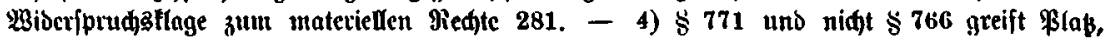

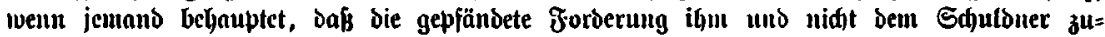

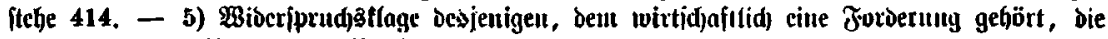
formell auf ben Ramen bes Bonftredungaffhulbuters geftellt wurò 415.

c) 3wangśvollftredung in bas unbeweglide Sernögen.

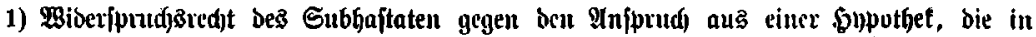

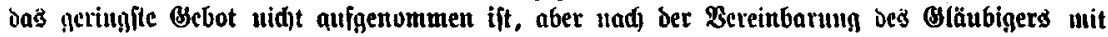

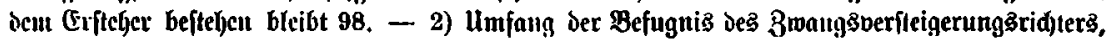

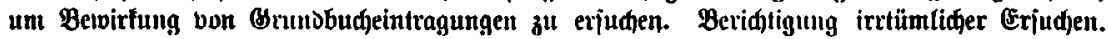

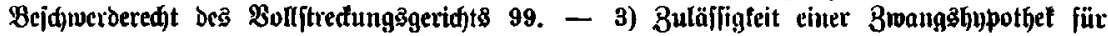
cine Forberung, für bic bereit ertaunter Binjen 407. - 5) Berfahren bei dem nad, Sdhfuis ber Berfleigerung, aber vor

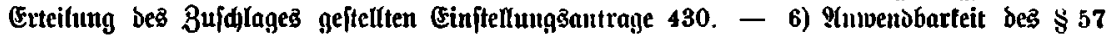
31vß3. auf Dietberträge, bic bor 1900 geidilvfien waren 431. - 7) Feine Bivifdenverjügung,

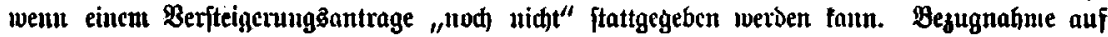

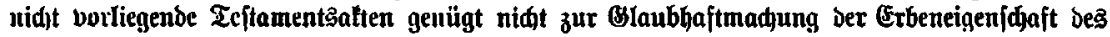
Subbaftaten 433. - 8) : Infechtung eines bei Der Berfteigerung abgegebenen (Mebuteš wegen

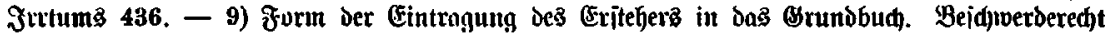

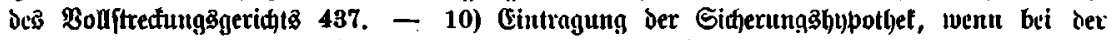

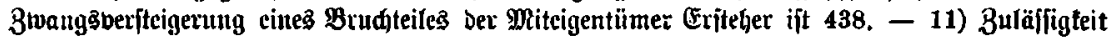

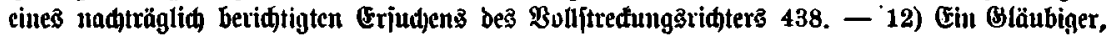
Der in Raufgelberbelegumgß̈termine nid)t viberiprach, wirt bei ber anderweiten Berteilung Des

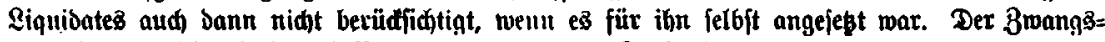
berwalter hat fein Medot auf Befriebigung aus oen Raufgeldern 441. 


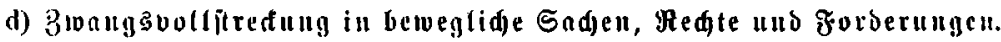

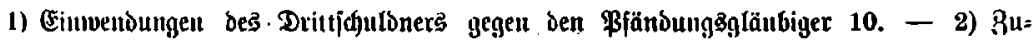

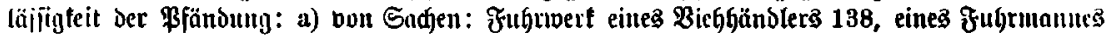

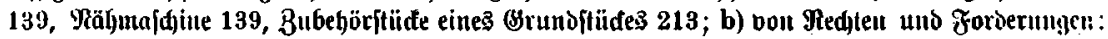

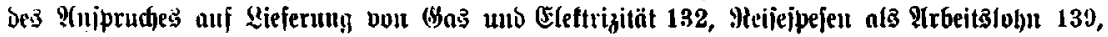

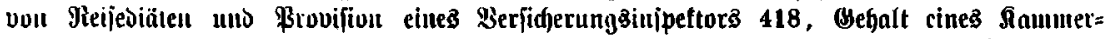

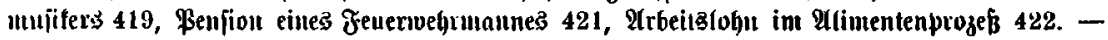

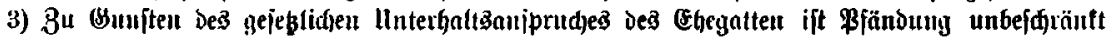

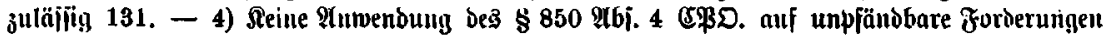

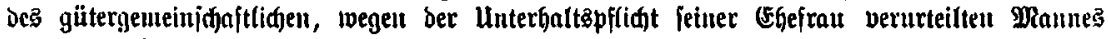

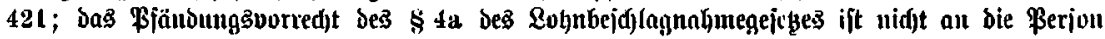

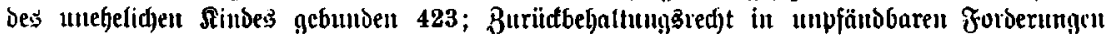

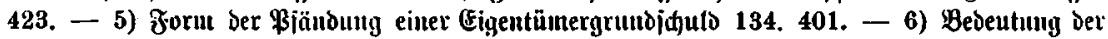

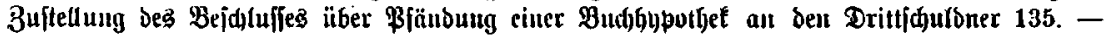

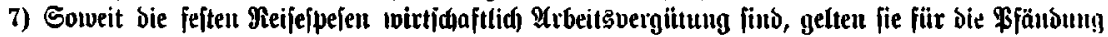

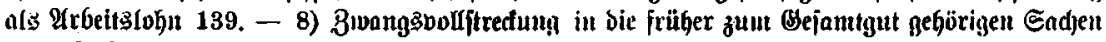

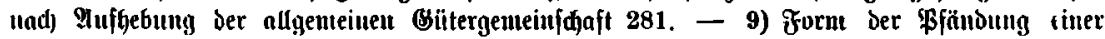

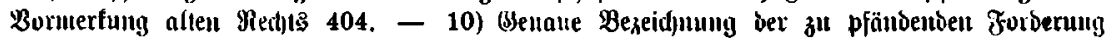

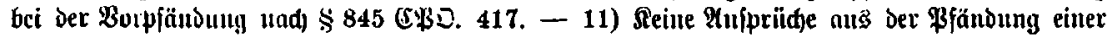

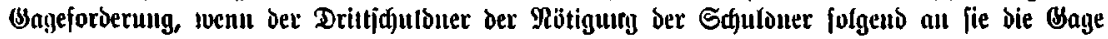
zahlt 416.

\section{Dffenbarungḡeio.}

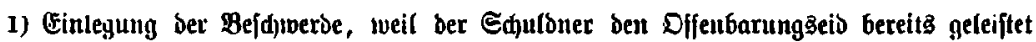

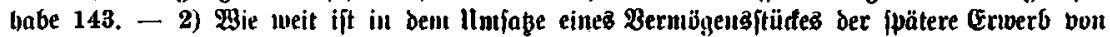

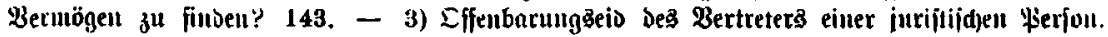

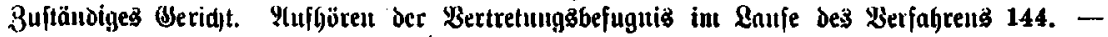

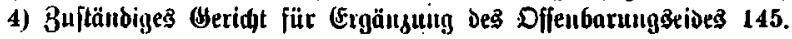

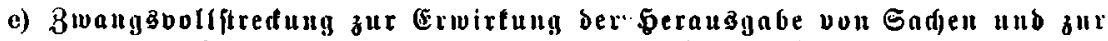

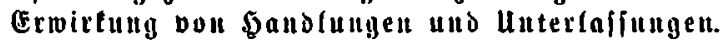

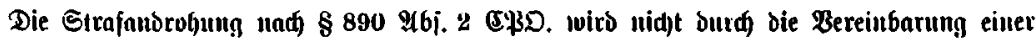

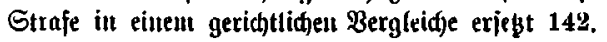

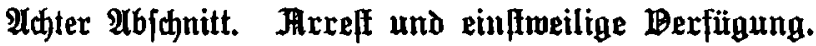

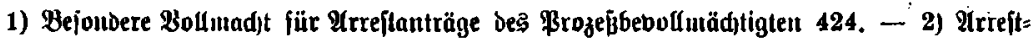

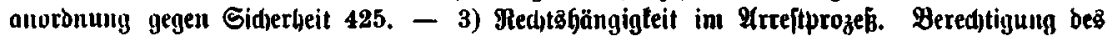

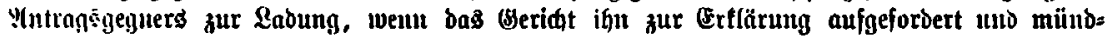

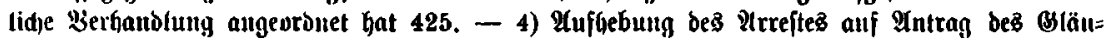

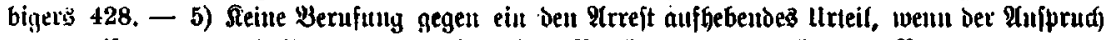

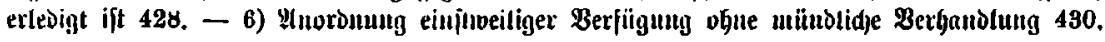

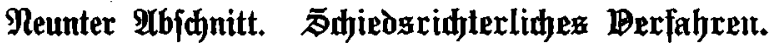

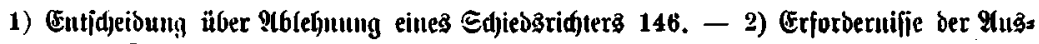

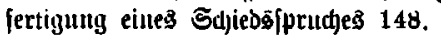

\section{Roukursrednt. \\ (Erfter $\mathfrak{A b}$ fdnitt. Whaterielles Winkuraredyt.}

a) Altgemeiue Beitimunugen.

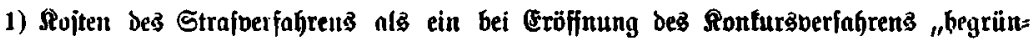

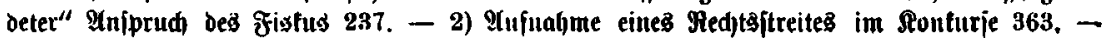
3) $\mathfrak{R a d y a h l u n g z p e r i p r e d j e n ~ n a d ) ~ 3 r o a n g e b e r g l e i d ) ~} \mathbf{3 6 9}$. 
b) $\mathscr{M}$ fed tung.

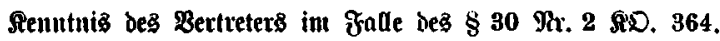

c) Routurggläubiger.

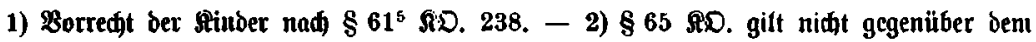

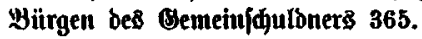

\section{3weiter $\mathfrak{A b}$ [dnitt. Kknnkuxanexfahren.}

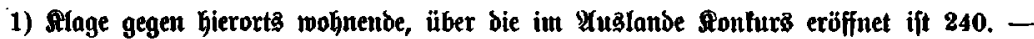

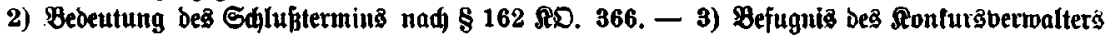

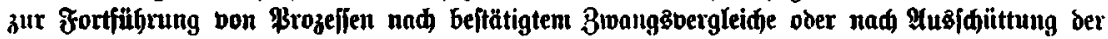
Mafie 366. - 4) \$lage bes Berivalters im Sonhurje einer Benofienjafaft auf Feftftellung

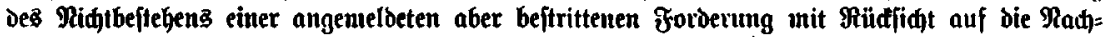

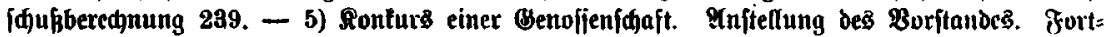

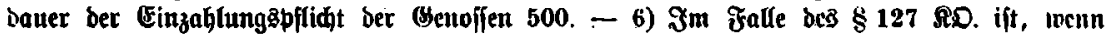

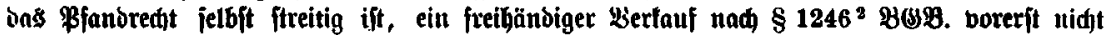

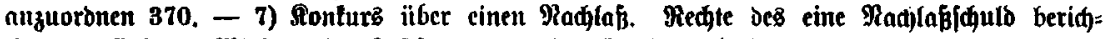
tigenden Erben. Birtung ber Feftitellung in ber SPonfurstubelle 68.

\section{Stautstedt.}

a) Redutsoerhältniffe ber Beamten.

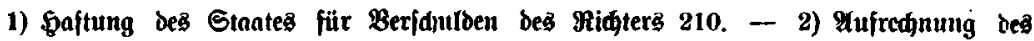

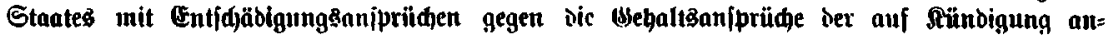

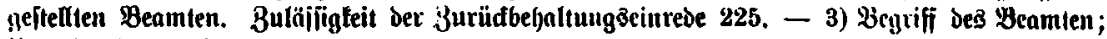
Itnterjajied bon Sufbeamten $41 \mathrm{y}$.

b) Sonftige öffentlidredtlide Berhältniffe.

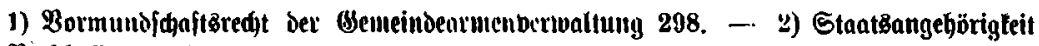
eineg Berjudtentell 305.

Bortregifter . . . . . . . . . . . . . . . . . . 513

Radtiträge . . . . . . . . . . . . . . . . . . . 527

Beridtigungen :. . . . . . . . . . . . . . . 528 